\title{
Article \\ Reliability Analysis of the New Exponential Inverted Topp-Leone Distribution with Applications
}

\author{
Ahmed Sayed M. Metwally ${ }^{1}{ }^{\mathbb{D}}$, Amal S. Hassan ${ }^{2} \mathbb{D}$, Ehab M. Almetwally ${ }^{3, * \mathbb{D}}$, B M Golam Kibria ${ }^{4} \mathbb{D}$ \\ and Hisham M. Almongy 5
}

1 Department of Mathematics, College of Science, King Saud University, Riyadh 11451, Saudi Arabia; dalsayed@ksu.edu.sa

2 Department of Mathematical Statistics, Faculty of Graduate Studies for Statistical Research, Cairo University, Giza 12613, Egypt; amal52_soliman@cu.edu.eg

3 Department of Statistics, Faculty of Business Administration, Delta University of Science and Technology, Gamasa 11152, Egypt

4 Department of Mathematics and Statistics, Florida International University (FIU), 11200 SW 8th St, Miami, FL 33199, USA; kibriag@fiu.edu

5 Department of Applied Statistics and Insurance, Faculty of Commerce, Mansoura University, El-Mansoura 35516, Egypt; elmongyh@mans.edu.eg

* Correspondence: ehabxp_2009@hotmail.com

check for updates

Citation: Metwally, A.S.M.; Hassan, A.S.; Almetwally, E.M.; Kibria, B.M.G.; Almongy, H.M. Reliability Analysis of the New Exponential Inverted Topp-Leone Distribution with Applications. Entropy 2021, 23, 1662. https://doi.org/10.3390/ e23121662

Academic Editor: Ali

Mohammad-Djafari

Received: 12 October 2021

Accepted: 6 December 2021

Published: 10 December 2021

Publisher's Note: MDPI stays neutral with regard to jurisdictional claims in published maps and institutional affiliations.

Copyright: (C) 2021 by the authors. Licensee MDPI, Basel, Switzerland. This article is an open access article distributed under the terms and conditions of the Creative Commons Attribution (CC BY) license (https:// creativecommons.org/licenses/by/ $4.0 /)$.

\begin{abstract}
The inverted Topp-Leone distribution is a new, appealing model for reliability analysis. In this paper, a new distribution, named new exponential inverted Topp-Leone (NEITL) is presented, which adds an extra shape parameter to the inverted Topp-Leone distribution. The graphical representations of its density, survival, and hazard rate functions are provided. The following properties are explored: quantile function, mixture representation, entropies, moments, and stressstrength reliability. We plotted the skewness and kurtosis measures of the proposed model based on the quantiles. Three different estimation procedures are suggested to estimate the distribution parameters, reliability, and hazard rate functions, along with their confidence intervals. Additionally, stress-strength reliability estimators for the NEITL model were obtained. To illustrate the findings of the paper, two real datasets on engineering and medical fields have been analyzed.
\end{abstract}

Keywords: new exponential-X; stress-strength reliability; entropy; Bayesian; maximum product spacing

\section{Introduction}

There are several univariate continuous distributions in the present statistical literature that may be used in a range of data modeling applications. However, it appears that the many distributions that are available are insufficient to manage the diverse data encountered in fields such as medicine, engineering, demography, biology, actuarial science, economics, finance, and reliability. Statistical and applied researchers are interested in constructing new extended continuous distributions that are more effective for data modeling. Adding parameters, compounding, generating, transformation, and composition are all methods for extending well-known distributions.

In the last couple of decades, the generation of new families of continuous distributions has attracted several statisticians to develop new models. Our interest is particularly in a new family proposed by Huo et al. [1] called the new exponential-X (NE-X) family. The cumulative distribution function (CDF) and probability density function (PDF) of the NE- $X$ family are defined as:

$$
F(x ; \theta, \zeta)=1-\left[\frac{1-G(x ; \zeta)^{2}}{1-(1-\theta) G(x ; \zeta)^{2}}\right]^{\theta}
$$


and

$$
f(x ; \theta, \zeta)=2 \theta^{2} g(x ; \zeta) G(x ; \zeta) \frac{\left[1-G(x ; \zeta)^{2}\right]^{\theta-1}}{\left[1-(1-\theta) G(x ; \zeta)^{2}\right]^{\theta+1}},
$$

where $g(x ; \zeta)$ and $G(x ; \zeta)$ are the PDF and CDF, respectively, for any baseline distribution with the set of parameters $\zeta$. The set of parameters $\zeta$ can contain more than one parameter according to the type of distribution, and $\theta$ is a parameter of NE-X family where $\theta>0$.

Inverted or inverse distributions are important in many fields, including biological sciences, life test problems, chemistry data, medical sciences, and so on, because of their applicability. Inverted conformation distributions have a different structure than noninverted conformation distributions in terms of density and hazard functions. The reader can consult Barco et al. [2], Abd AL-Fattah et al. [3], Hassan and Abd-Allah [4], Hassan and Mohamed [5], Muhammed [6], Hassan and Mohamed [7], Almetwally [8], and Hassan and Nassr [9] for discussions and applications of inverted distributions.

The inverted Topp-Leone (ITL) distribution with only one shape parameter $(\delta \geq 0)$, which was presented by Hassan et al. [10], is a recent, significant model among the wellknown inverted distributions. It density and hazard functions take different shapes according to value of $\delta$, including unimodal, right skewed, increasing, decreasing, and upside down. The PDF and CDF of the ITL distribution are specified, respectively, as follows:

$$
G(x ; \delta)=1-\frac{(1+2 x)^{\delta}}{(1+x)^{2 \delta}} ; \quad x \geq 0, \delta>0,
$$

and,

$$
g(x ; \delta)=2 \delta x \frac{(1+2 x)^{\delta-1}}{(1+x)^{2 \delta+1}} ; \quad x, \delta>0 .
$$

Some authors studied and developed new extensions and generalizations of the ITL distribution, such as the power ITL distribution prepared by Abushal et al. [11], Kumaraswamy ITL distribution introduced by Hassen et al. [12], alpha power ITL distribution presented by Ibrahim et al. [13], modified Kies ITL distribution introduced by Almetwally et al. [14], odd Weibull ITL distribution suggested by Almetwally [15], and half logistic ITL distribution prepared by Bantan et al. [16].

In this paper, a new ITL distribution based on the NE-X family is proposed. We call it the new exponential ITL (NEITL) distribution. Our motivations for presenting the NEITL distribution are as follows: (i) to increase the flexibility of the ITL distribution for modeling several types of data; (ii) to allow researches to obtain more flexible density and hazard rate functions; (iii) real-world examples from medical, engineering, and other fields demonstrate that the NEITL model outperforms other competing distributions, justifying its implementation in these domains.

Another motivation for the present study was estimating the NEITL parameters, reliability function, and hazard rate function using three estimation methods to recommend the best estimates via a simulation study. The suggested procedures are maximum likelihood (ML), maximum product of spacing (MPS), and Bayesian procedures. The asymptotic and bootstrap confidence intervals are shown. Furthermore, we obtained the stress-strength (S-S) reliability estimator assuming that both the strength $\left(X_{1}\right)$ and stress $\left(X_{2}\right)$ have NEITLs with different shape parameters. In simulation research, statistical analysis was performed between these methods to assess their effectiveness and to investigate how these estimators function for various sample sizes and parameter values. Two applications showed that the NEITL distribution provides a better fit than some other distributions.

The rest of this essay is presented as follows. In Section 2, we define the NEITL distribution. Some of the statistical features of the NEITL distribution are determined in Section 3. The NEITL distribution's reliability, hazard function (HF), and S-S reliability are covered in Section 4. Section 5 considers point estimate, asymptotic, and bootstrap confidence intervals utilizing ML, Bayesian, and MPS estimation methods. A simulation 
experiment is presented in Section 6 to compare the performances of the estimates presented in Section 5. Data implementations are explored in Section 7. The article is closed with some conclusions.

\section{NEITL Distribution}

The two-parameter NEITL distribution is a special model of the NE-X family with the ITL distribution as a baseline function. We get the CDF and PDF of the NEITL distribution by replacing the CDF and PDF of the ITL model in (1) and (2), respectively.

$$
F(x ; \Omega)=1-\left[\frac{1-\left[1-\frac{(1+2 x)^{\delta}}{(1+x)^{2 \delta}}\right]^{2}}{1-(1-\theta)\left[1-\frac{(1+2 x)^{\delta}}{(1+x)^{2 \delta}}\right]^{2}}\right]^{\theta} ; x>0, \theta, \delta>0,
$$

and

$$
f(x ; \Omega)=4 \theta^{2} \delta x \frac{(1+2 x)^{\delta-1}}{(1+x)^{2 \delta+1}}\left[1-\frac{(1+2 x)^{\delta}}{(1+x)^{2 \delta}}\right] \frac{\left(1-\left[1-\frac{(1+2 x)^{\delta}}{(1+x)^{2 \delta}}\right]^{2}\right)^{\theta-1}}{\left(1-(1-\theta)\left[1-\frac{(1+2 x)^{\delta}}{(1+x)^{2 \delta}}\right]^{2}\right)^{\theta+1}} ; x>0, \theta, \delta>0,
$$

where $\Omega$ is a vector of parameters $(\delta, \theta)$ for this distribution. Figure 1 visually displays the PDF plots and 3-D plots of $X$ using NEITL and parameters $(\Omega)$. The NEITL distribution may be right-skewed and unimodal, according to the PDF plots.

Furthermore, we obtain an explicit linear representation of the density and distribution functions by using the generalized binomial expansion. Hence, for $k>0$, the $k$ is a real non-integer, and for $z<1$ we use the following expansion with negative power:

$$
(1-z)^{-k}=\sum_{i=0}^{\infty}\left(\begin{array}{c}
i+k-1 \\
k-1
\end{array}\right) z^{i}
$$

Additionally, we use the binomial expansion below with positive power:

$$
(1-w)^{v}=\sum_{j=0}^{\infty}\left(\begin{array}{c}
v \\
j
\end{array}\right)(-1)^{j} w^{j}
$$

Let $z=(1-\theta) G(x ; \zeta)^{2}$, and $w=G(x ; \zeta)^{2}$. Then, the linear representation of CDF for NE-X family (1) is given by

$$
F(x ; \Omega)=1-\sum_{i, j=0}^{\infty}\left(\begin{array}{c}
i+\theta-1 \\
\theta-1
\end{array}\right)\left(\begin{array}{l}
\theta \\
j
\end{array}\right)(-1)^{j}(1-\theta)^{i} G(x ; \zeta)^{2(i+j)} .
$$

By applying the previous expansion (7) on ITL distribution (3), we have CDF of the NEITL distribution in an expanded form as the following:

$$
F(x ; \Omega)=1-\sum_{i, j=0}^{\infty}\left(\begin{array}{c}
i+\theta-1 \\
\theta-1
\end{array}\right)\left(\begin{array}{l}
\theta \\
j
\end{array}\right)(-1)^{j}(1-\theta)^{i}\left[1-\frac{(1+2 x)^{\delta}}{(1+x)^{2 \delta}}\right]^{2(i+j)},
$$

and let $u=2(i+j)$, and $v=\theta-1$. Then, the CDF of the NEITL distribution can be rewritten as follows:

$$
F(x ; \Omega)=1-\sum_{i, j=0}^{\infty} \sum_{l=0}^{u}\left(\begin{array}{c}
i+v \\
v
\end{array}\right)\left(\begin{array}{l}
\theta \\
j
\end{array}\right)\left(\begin{array}{l}
u \\
l
\end{array}\right)(-1)^{j+l}(1-\theta)^{i} \frac{(1+2 x)^{l \delta}}{(1+x)^{2 l \delta}} .
$$


Hence, the CDF (9) is represented as an infinite linear combination of the ITL distribution function with parameter $l \delta$.

In addition to the expression (9), we derive PDF expression of the NEITL distribution distribution as follows:

Let $z=(1-\theta) G(x ; \delta)^{2}$. Then the linear representation of PDF for NE-X family (2) is given by

$$
f(x ; \Omega)=2 \theta^{2} \sum_{i, j=0}^{\infty}\left(\begin{array}{c}
i+\theta \\
\theta
\end{array}\right)\left(\begin{array}{l}
v \\
j
\end{array}\right)(-1)^{j}(1-\theta)^{i} g(x ; \delta) G(x ; \delta)^{u+1} .
$$

Using CDF (3) and PDF (4) in (10), and binomial expansion, we obtain the following expansion:

$$
f(x ; \Omega)=2 \delta x \sum_{i, j=0}^{\infty} \sum_{l=0}^{u+1} K_{i, j, l} \frac{(1+2 x)^{\delta(l+1)-1}}{(1+x)^{2 \delta(l+1)+1}},
$$

where $K_{i, j, l}=\frac{2 \theta^{2}}{l+1}\left(\begin{array}{c}i+\theta \\ \theta\end{array}\right)\left(\begin{array}{c}v \\ j\end{array}\right)\left(\begin{array}{c}u+1 \\ l\end{array}\right)(-1)^{j+l}(1-\theta)^{i}$. It is the PDF function of the ITL distribution with parameter $\delta(l+1)$.

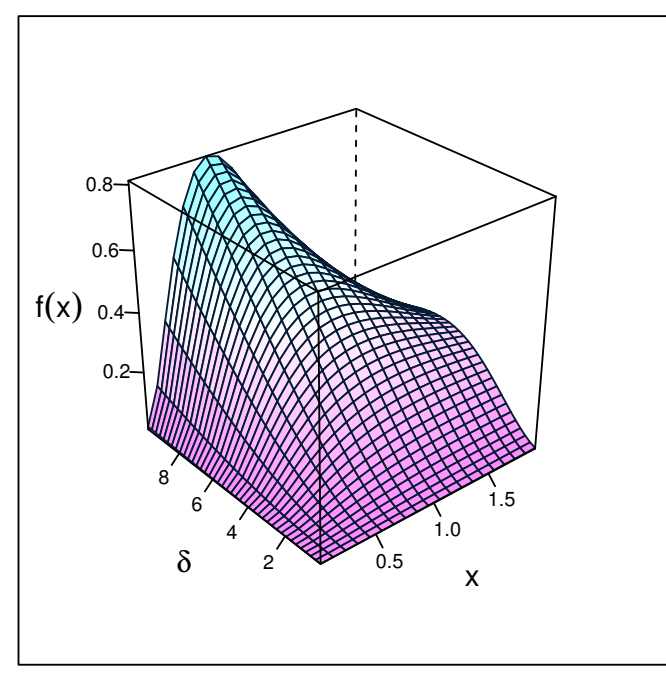

$\theta=0.5$

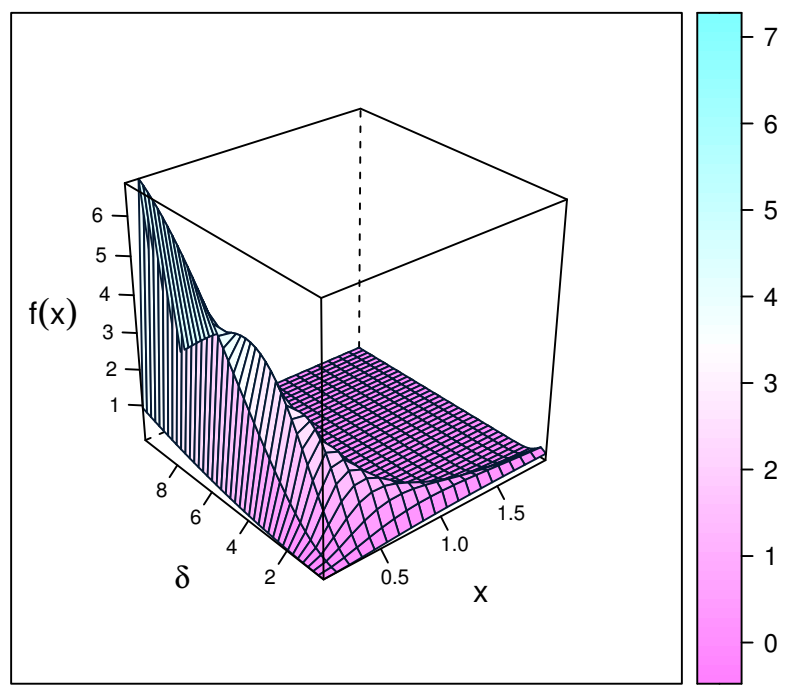

$\theta=5$
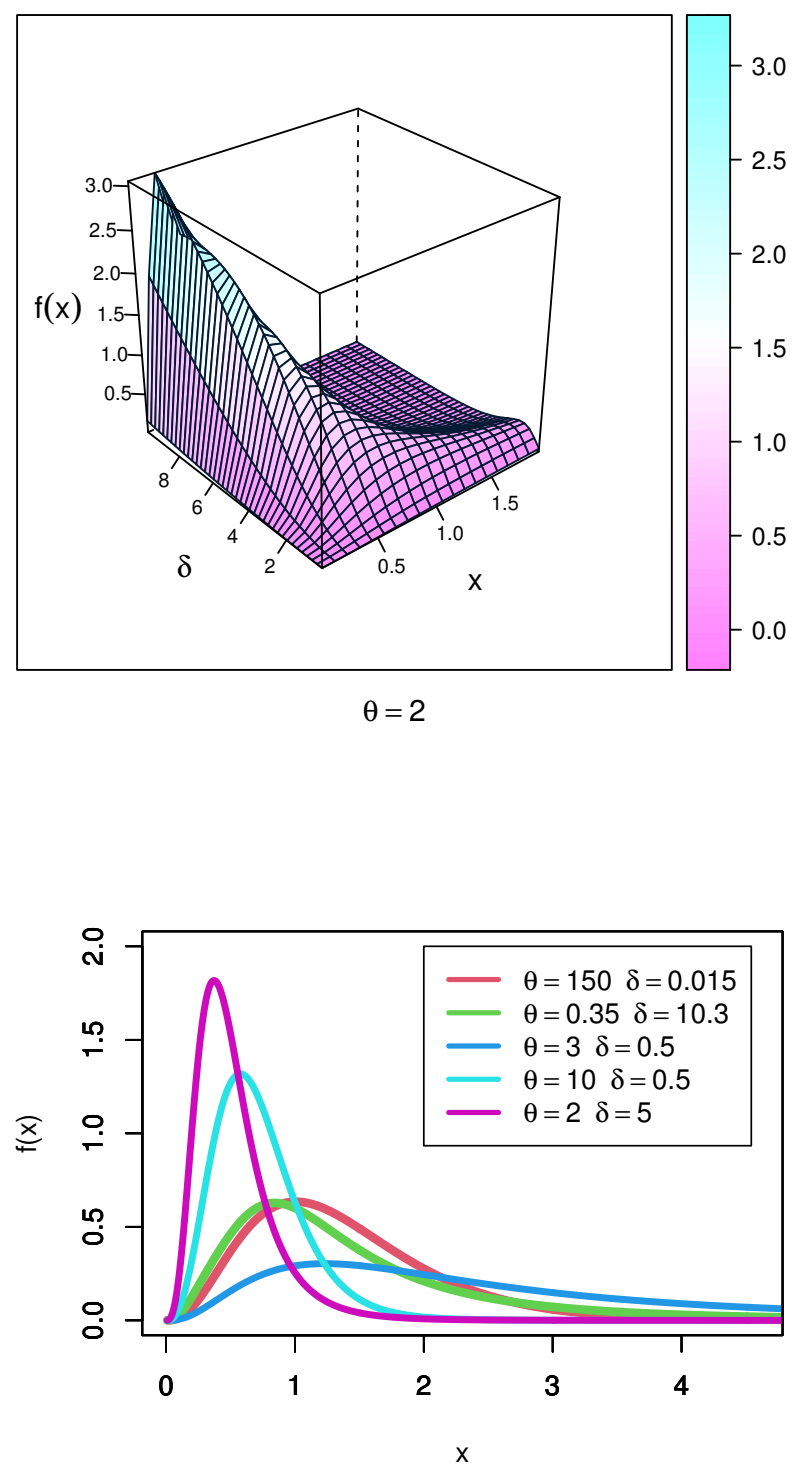

Figure 1. PDFs plots of the NEITL distribution. 


\section{Mathematical Properties}

Here, some structure properties of the NEITL distribution are investigated, such as ordinary and incomplete moments, the quantile function and random number generation, Rényi and $\rho$-entropies, and the $\mathrm{S}-\mathrm{S}$ reliability model.

\subsection{Ordinal Moments}

The $r$ th moment of the NEITL distribution is given by

$$
\begin{aligned}
E\left(X^{r}\right) & =2 \delta \sum_{i, j=0}^{\infty} \sum_{l=0}^{u+1} K_{i, j, l} \int_{0}^{\infty} x^{r+1} \frac{(1+2 x)^{\delta(l+1)-1}}{(1+x)^{2 \delta(l+1)+1}} d x \\
& =2 \delta \sum_{i, j=0}^{\infty} \sum_{l=0}^{u+1} K_{i, j, l} \int_{0}^{\infty} x^{r+1} \frac{\left(1+\frac{x}{x+1}\right)^{\delta(l+1)-1}}{(1+x)^{\delta(l+1)+2}} d x
\end{aligned}
$$

Using the binomial expansion in (12), we can define $(1+z)^{\delta(l+1)-1}=\sum_{q=0}^{\infty}\left(\begin{array}{c}\delta(l+1)-1 \\ q\end{array}\right) z^{q}$. Let $z=\frac{x}{x+1} ; \quad 0<z<1$. Then the $r$ th moment of the NEITL distribution has the form

$$
E\left(X^{r}\right)=2 \delta \sum_{i, j, q=0}^{\infty} \sum_{l=0}^{u+1} \tau_{i, j, l, q} \beta(r+q+2, \delta(l+1)-r),
$$

where $\beta(a, b)=\int_{0}^{1} z^{a-1}(1-z)^{b-1} d z$ and $\tau_{i, j, l, q}=K_{i, j, l}(\underset{q}{\delta(l+1)-1})$. Furthermore, the $m$ th central moment of $\mathrm{X}$ is given by

$$
\mu_{r}^{\prime}=E\left(x-\mu_{1}^{\prime}\right)^{r}=\sum_{k=0}^{r}(-1)^{k}\left(\begin{array}{l}
r \\
k
\end{array}\right)\left(\mu_{1}^{\prime}\right)^{k} \mu_{r-k}^{\prime} .
$$

Table 1 gives some different statistical measures such as mean $\left(\mu_{1}^{\prime}\right)$, variance $\left(\sigma^{2}\right)$, skewness (SK), and kurtosis (KU) for some values of parameters.

Table 1. Moments measures for NEITL distribution.

\begin{tabular}{ccccc}
\hline$(\boldsymbol{\delta}, \boldsymbol{\theta})$ & $\boldsymbol{\mu}_{\mathbf{1}}^{\prime}$ & $\boldsymbol{\sigma}^{\mathbf{2}}$ & SK & KU \\
\hline$(2,3)$ & 0.739 & 0.204 & 2.624 & 23.372 \\
$(3,3)$ & 0.534 & 0.083 & 1.871 & 11.412 \\
$(5,3)$ & 0.369 & 0.032 & 1.409 & 7.371 \\
$(5,4)$ & 0.293 & 0.016 & 1.07 & 5.572 \\
$(5,5)$ & 0.248 & 0.01 & 0.847 & 4.602 \\
$(1,5)$ & 0.787 & 0.192 & 2.089 & 17.382 \\
$(2,7)$ & 0.414 & 0.048 & 1.599 & 8.225 \\
$(3,7)$ & 0.295 & 0.018 & 1.222 & 6.201 \\
\hline
\end{tabular}

From Table 1, we conclude that the NEITL distribution is skewed to the right and leptokurtic.

\subsection{Incomplete Moments}

The $r$ th incomplete moment, say, $\eta_{r}(y)$ of $X$, is obtained from (11) as follows:

$$
\begin{aligned}
\eta_{r}(y) & =2 \delta \sum_{i, j=0}^{\infty} \sum_{l=0}^{u+1} K_{i, j, l} \int_{0}^{y} \frac{x^{r+1}}{(1+x)^{2 \delta(l+1)+2}}\left(1+\frac{x}{1+x}\right)^{\delta(l+1)-1} d x \\
& =2 \delta \sum_{i, j, q=0}^{\infty} \sum_{l=0}^{u+1} \tau_{i, j, l, q} \beta\left(r+q+2, \delta(l+1)-r, \frac{y}{1+y}\right)
\end{aligned}
$$


where $\beta(., . t)$ stands for an incomplete beta function. The first incomplete moment, for $r=1$ in (14), is obtained. The famous applications of the first incomplete moment are the Lorenz and Bonferroni curves which are defined, respectively, by $\operatorname{Lz}(m)=\frac{\eta_{1}(m)}{\mu_{1}^{\prime}}$ and $B u(m)=\frac{L z(m)}{F(m)}$.

\subsection{Quantile Function}

The quantile function of the NEITL distribution, say, $x=Q(x)=F^{-1}(u)$, is derived by inverting (5) as follows:

$$
x=\sqrt{v^{2}-v}-v,
$$

where $v=1-\left[1-\sqrt{\frac{(1-u)^{\frac{1}{\theta}}-1}{(1-\theta)(1-u)^{\frac{1}{\theta}}-1}}\right]^{\frac{-1}{\delta}}$.

In particular, the first quartile, say, $Q_{1}$; the second quartile, say, $Q_{2}$; and the third quartile, say, $Q_{3}$ are obtained by setting $x=0.25,0.5$, and 0.75 , respectively, in (15). The Bowley's skewness depends on quartiles as follows:

$$
S K=\frac{Q(0.75)-2 Q(0.5)+Q(0.25)}{Q(0.75)-Q(0.5)},
$$

where $Q($.$) is the NEITL quantile function. The Moor's kurtosis is given as$

$$
K U=\frac{Q(0.875)-Q(0.625)-Q(0.375)+Q(0.125)}{Q(0.75)-Q(0.25)} .
$$

Skewness and kurtosis plots of the NEITL distribution, based on quantiles, are exhibited in Figure 2.
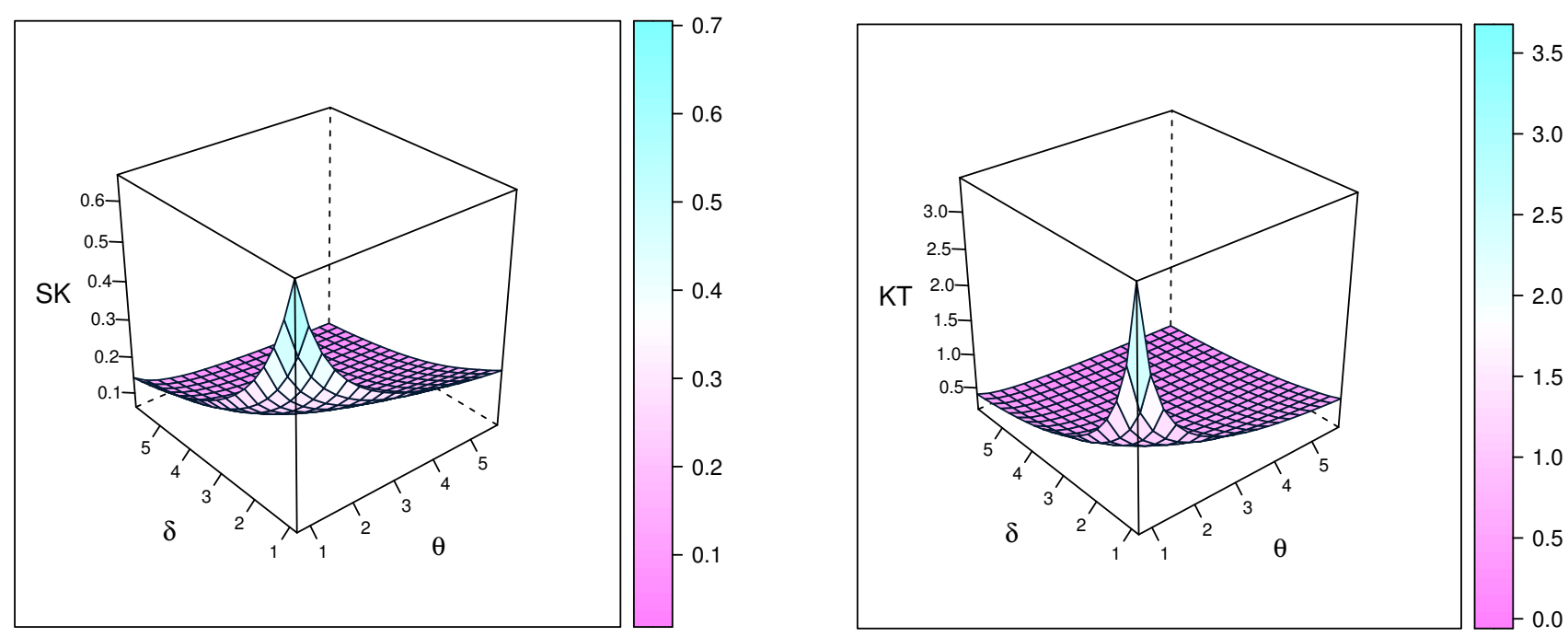

Figure 2. Plots of the skewness and kurtosis of the NEITL distribution.

\subsection{Rényi and Other Entropies}

Here, we obtain Rényi and $\rho$-entropies. The Rényi entropy, $\Xi(b)$, of a random variable $X$, is defined by

$$
\Xi(b)=\frac{1}{1-b} \log \left[\int_{0}^{\infty} f^{b}(x) d x\right],
$$

where $b>0$ and $b \neq 0$. Using expansions in (6) and after some simplification, then $f^{b}(x)$ should be written as: 


$$
f^{b}(x)=\sum_{i, j=0}^{\infty}(-1)^{j}\left(\begin{array}{c}
b(\theta+1)+i-1 \\
b(\theta+1)-1
\end{array}\right)\left(\begin{array}{c}
b(v) \\
j
\end{array}\right)(1-\theta)^{i}\left(4 \theta^{2} \delta x\right)^{b} \frac{(1+2 x)^{b(\delta-1)}}{(1+x)^{b(2 \delta+1)}}\left[1-\frac{(1+2 x)^{\delta}}{(1+x)^{2 \delta}}\right]^{b+2(j+i)} .
$$

Again, using the binomial expansions more than one times leads to

$$
f^{b}(x)=\sum_{i, j, k, m=0}^{\infty} \Psi_{i, j, k, m} x^{b+m}(1+x)^{-\delta k-b \delta-2 b-m},
$$

where $\Psi_{i, j, k, m}=(-1)^{j+k}\left(\begin{array}{c}b(\theta+1)+i-1 \\ b(\theta+1)-1\end{array}\right)\left(\begin{array}{c}b(v) \\ j\end{array}\right)\left(\begin{array}{c}b+u \\ k\end{array}\right)\left(\begin{array}{c}\delta k+b(\delta-1) \\ m\end{array}\right)(1-\theta)^{i}\left(4 \theta^{2} \delta\right)^{b}$. Substituting (20) in (18) gives

$$
\begin{aligned}
\Xi(b) & =\frac{1}{1-b} \log \left[\int_{0}^{\infty} \sum_{i, j, k, m=0}^{\infty} \Psi_{i, j, k, m} x^{b+m}(1+x)^{-\delta k-b(\delta+2)-m} d x\right] \\
& =\frac{1}{1-b} \log \left[\sum_{i, j, k, m=0}^{\infty} \Psi_{i, j, k, m} \beta(b+m+1, \delta k+b(\delta+1)-1)\right] .
\end{aligned}
$$

The $\rho$ entropy, $E(\rho)$, is defined as follows:

$$
E(\rho)=\frac{1}{\rho-1} \log \left[1-\int_{0}^{\infty} f^{\rho}(x) d x\right] ; \rho>0 \text { and } \rho \neq 0 .
$$

The $\rho$ entropy of the NEITL takes the form

$$
E(\rho)=\frac{1}{\rho-1} \log \left[1-\sum_{i, j, k, m=0}^{\infty} \Psi_{i, j, k, m} \beta(b+m+1, \delta k+b(\delta+1)-1)\right] .
$$

\section{Reliability Analysis}

In this section, we discus the reliability analysis in terms of hazard, survival, and S-S reliability for the NEITL distribution.

\subsection{Hazard and Survival Reliability}

The survival function (SF) of the NEITL distribution is given by

$$
S F(x ; \Omega)=\left[\frac{1-\left[1-\frac{(1+2 x)^{\delta}}{(1+x)^{2 \delta}}\right]^{2}}{1-(1-\theta)\left[1-\frac{(1+2 x)^{\delta}}{(1+x)^{2 \delta}}\right]^{2}}\right]^{\theta} ; x>0, \theta, \delta>0 .
$$

Figure 3 gives SF plots of the NEITL distribution for specific values of parameters. The HF of the NEITL distribution is given by

$$
H F(x ; \Omega)=4 \theta^{2} \delta x \frac{(1+2 x)^{\delta-1}}{(1+x)^{2 \delta+1}}\left[1-\frac{(1+2 x)^{\delta}}{(1+x)^{2 \delta}}\right] \frac{\left(1-\left[1-\frac{(1+2 x)^{\delta}}{(1+x)^{2 \delta}}\right]^{2}\right)^{-1}}{1-(1-\theta)\left[1-\frac{(1+2 x)^{\delta}}{(1+x)^{2 \delta}}\right.} .
$$

The HF plots of the NEITL distribution are displayed in Figure 4 to control sequence for certain values of parameters. These figures show that the HF of the NEITL distribution can be increasing, decreasing, or upside-down shaped. 


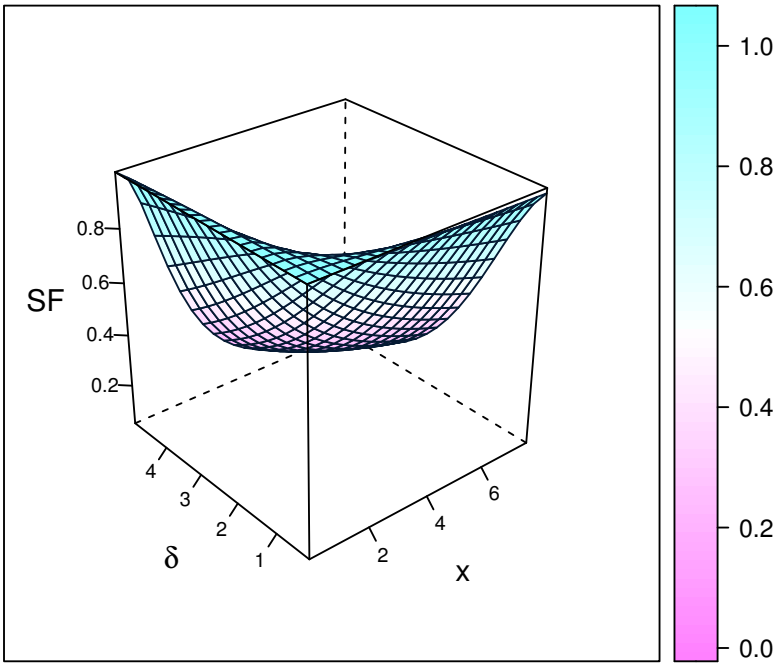

$\theta=0.5$

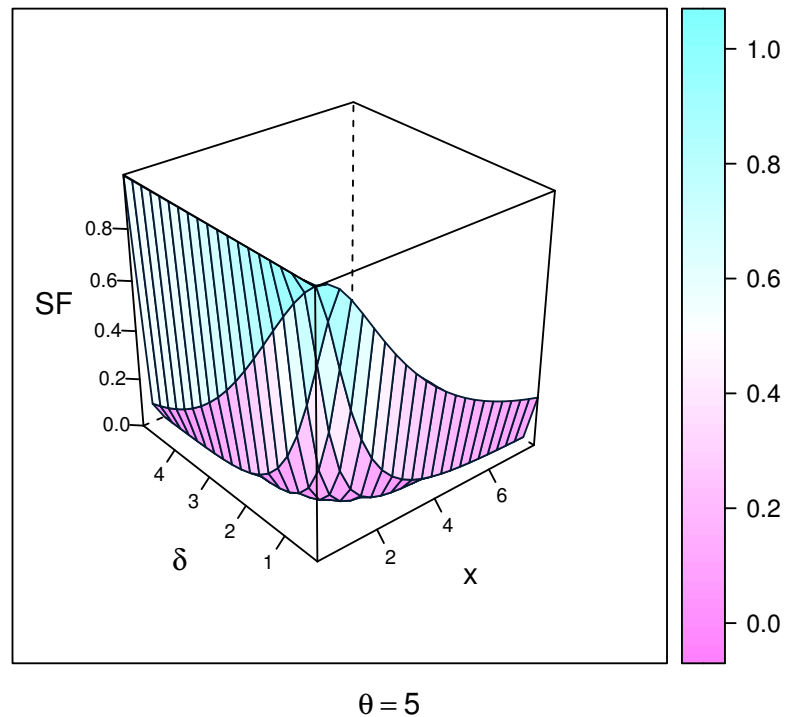

Figure 3. SF plots of the NEITL distribution.
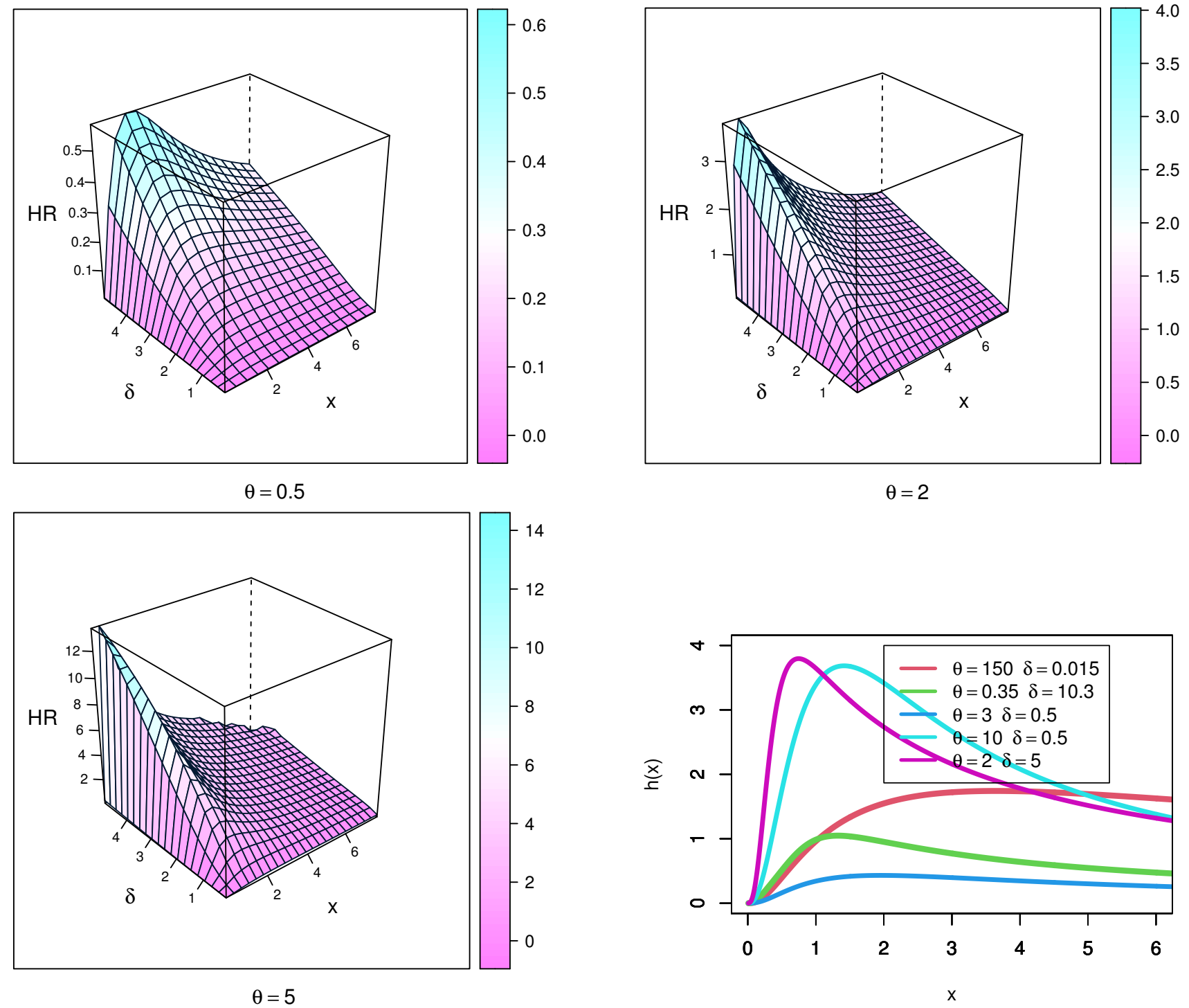

Figure 4. HF plots of the NEITL distribution. 


\subsection{Stress-Strength Reliability}

The stress-strength model is extensively used in reliability estimation. The S-S model has many applications in physics and engineering, including strength failure testing, structural modeling, estimating the deterioration of rocket motors, and modeling the static fatigue of ceramic components. In the S-S model, reliability $R$ measures the reliability of the component that has strength $X_{1}$ when it is subjected to random stress $X_{2}$. The component fails if the applied stress exceeds its strength: $R=P\left(X_{2}<X_{1}\right)$. For more information about this model, see Abu El Azm et al. [17], Sabry et al. [18], Yousef and Almetwally [19], and Hassan et al. [20]. Let $X_{1}$ and $X_{2}$ be two independent random variables with $\operatorname{NEITL}\left(\delta_{1}, \theta\right)$ and $\operatorname{NEITL}\left(\delta_{2}, \theta\right)$ distributions, respectively. Hence, the $S-S$ reliability is obtained, using the same expansions in (9) and (11) with different indicators, as follows:

$$
\begin{aligned}
R & =1-A^{*} 4 \theta^{2} \delta_{1} \int_{0}^{\infty} x \frac{(1+2 x)^{\delta_{1}\left(l_{1}+1\right)+l_{2} \delta_{2}-1}}{(1+x)^{2 \delta_{1}\left(l_{1}+1\right)+2 l_{2} \delta_{2}+1}} d x \\
& =1-A^{*} \frac{2 \theta^{2} \delta_{1}}{\delta_{1}\left(l_{1}+1\right)+\delta_{2} l_{2}} \int_{0}^{\infty} 2\left(\delta_{1}\left(l_{1}+1\right)+\delta_{2} l_{2}\right) x \frac{(1+2 x)^{\delta_{1}\left(l_{1}+1\right)+l_{2} \delta_{2}-1}}{(1+x)^{2 \delta_{1}\left(l_{1}+1\right)+2 l_{2} \delta_{2}+1}} d x \\
& =1-A^{*} \frac{2 \theta^{2} \delta_{1}}{\delta_{1}\left(l_{1}+1\right)+\delta_{2} l_{2}}
\end{aligned}
$$

where $A^{*}=C_{1} C_{2}\left(\begin{array}{c}u_{2} \\ l_{2}\end{array}\right)(-1)^{j_{2}+j_{1}+l_{2}+l_{1}}(1-\theta)^{i_{2}+i_{2}}, C_{1}=\sum_{i_{1}, j_{1}=0}^{\infty} \sum_{l_{1}=0}^{u_{1}+1}\left(\begin{array}{c}i_{1}+\theta \\ \theta\end{array}\right)\left(\begin{array}{c}v \\ j_{1}\end{array}\right)\left(\begin{array}{c}u_{1}+1 \\ l_{1}\end{array}\right)$, $C_{2}=\sum_{i_{2}, j_{2}=0}^{\infty} \sum_{l_{2}=0}^{u_{2}}\left(\begin{array}{c}i_{2}+v \\ v\end{array}\right)\left(\begin{array}{c}\theta \\ j_{2}\end{array}\right), u_{1}=2\left(i_{1}+j_{1}\right)$ and $u_{2}=2\left(i_{2}+j_{2}\right)$. Plots of S-S model for some values of parameters are given in Figure 5.

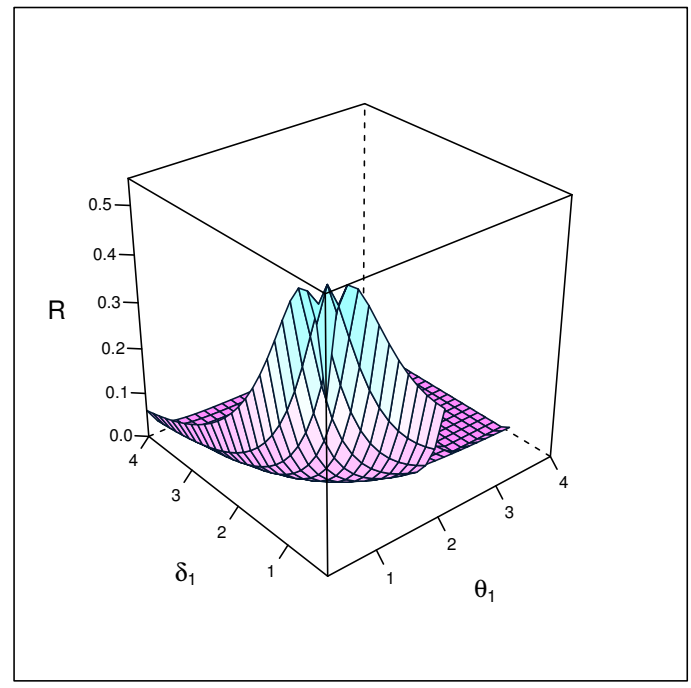

$\theta_{2}=0.5 \quad \delta_{2}=0.5$

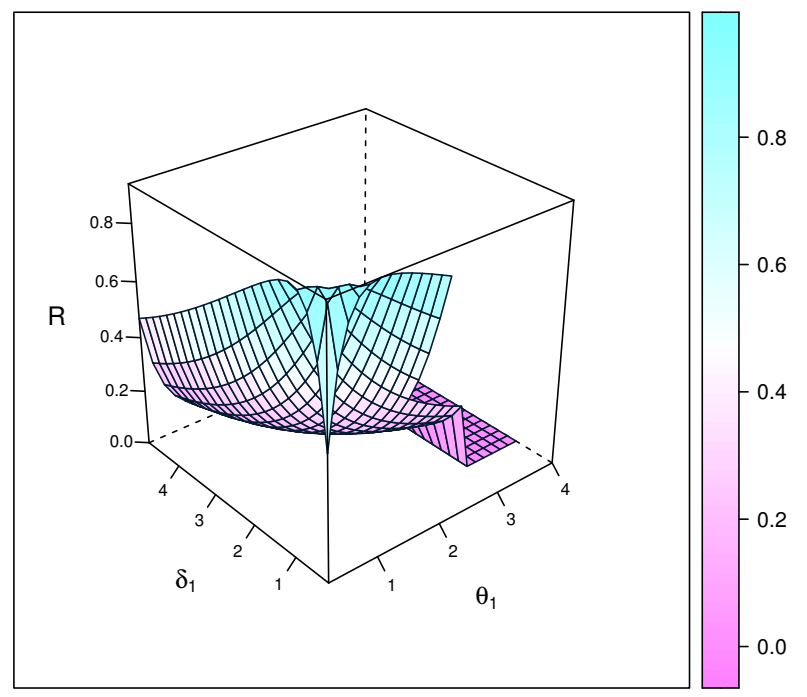

$\theta_{2}=2.5 \quad \delta_{2}=0.5$

Figure 5. Cont. 


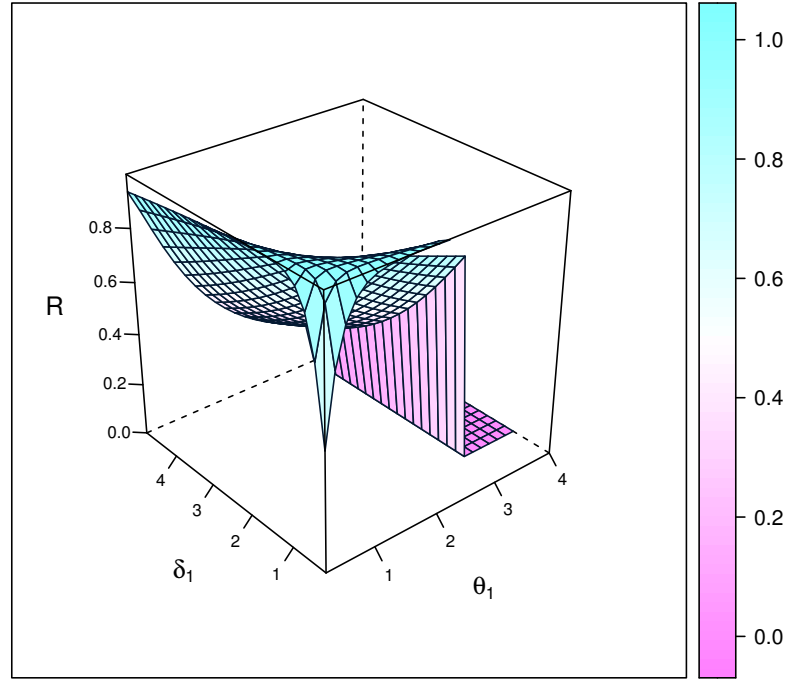

$\theta_{2}=2.5 \delta_{2}=2.5$

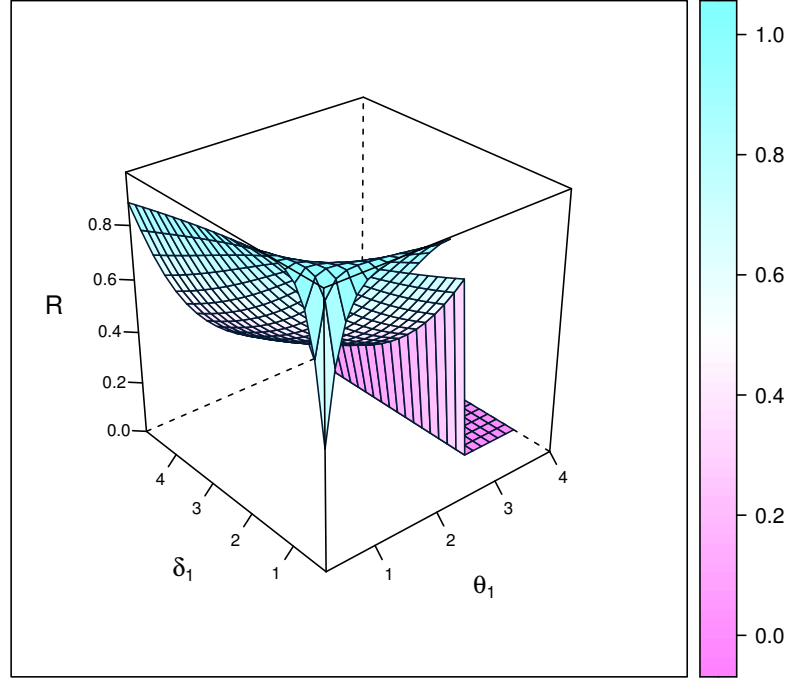

$\theta_{2}=1 \delta_{2}=5.5$

Figure 5. Stress-strength plots of the NEITL distribution.

\section{Parameter Estimation}

In this section, we use different point estimation methods to estimate the unknown parameters of the NEITL distribution. We use classical (ML and MPS) and non-classical (Bayesian) methods. In the last few years, parameter estimation using different methods has received great attention from many authors, such as Haj Ahmad and Almetwally [21], Basheer et al. [22], and Almetwally [15].

\subsection{Maximum Likelihood Method}

Let $x_{1}, \cdots, x_{n}$ be a random sample from the NEITL distribution with parameters $\theta$ and $\delta$. The log-likelihood function of the NEITL can be written as:

$$
l(\Omega)=4^{n} \theta^{2 n} \delta^{n} \prod_{i=1}^{n}\left[x_{i} \frac{\left(1+2 x_{i}\right)^{\delta-1}}{\left(1+x_{i}\right)^{2 \delta+1}}\left[1-A_{i}(\delta)\right] \frac{\left(1-\left[1-A_{i}(\delta)\right]^{2}\right)^{\theta-1}}{\left(1-(1-\theta)\left[1-A_{i}(\delta)\right]^{2}\right)^{\theta+1}}\right],
$$

where $A_{i}(\delta)=\frac{\left(1+2 x_{i}\right)^{\delta}}{\left(1+x_{i}\right)^{2 \delta}}$. The log-likelihood function of the NEITL distribution is

$$
\begin{aligned}
\ell(\Omega)= & n(\ln (4)+2 \ln (\theta)+\ln (\delta))+\sum_{i=1}^{n} \ln \left(x_{i}\right)+(\delta-1) \sum_{i=1}^{n} \ln \left(1+2 x_{i}\right)+\sum_{i=1}^{n} \ln \left[1-A_{i}(\delta)\right]- \\
& (2 \delta+1) \sum_{i=1}^{n} \ln \left(1+x_{i}\right)+(\theta-1) \sum_{i=1}^{n} \ln \left(1-\left[1-A_{i}(\delta)\right]^{2}\right)-(\theta+1) \sum_{i=1}^{n} \ln \left(1-(1-\theta)\left[1-A_{i}(\delta)\right]^{2}\right) .
\end{aligned}
$$

The ML estimators are obtained by solving the following equations:

$$
\begin{gathered}
\frac{\partial \ell(\Omega)}{\partial \theta}=\frac{2 n}{\theta}+\sum_{i=1}^{n} \ln \left(1-\left[1-A_{i}(\delta)\right]^{2}\right)-\sum_{i=1}^{n} \ln \left(1-(1-\theta)\left[1-A_{i}(\delta)\right]^{2}\right)- \\
(\theta+1) \sum_{i=1}^{n} \frac{\left[1-A_{i}(\delta)\right]^{2}}{1-(1-\theta)\left[1-A_{i}(\delta)\right]^{2}}
\end{gathered}
$$


and

$$
\begin{aligned}
\frac{\partial \ell(\Omega)}{\partial \delta}= & \frac{n}{\delta}+\sum_{i=1}^{n} \ln \left(1+2 x_{i}\right)+(v) \sum_{i=1}^{n} \frac{2\left[1-A_{i}(\delta)\right] A_{i}(\delta) \ln \left[\frac{\left(1+2 x_{i}\right)}{\left(1+x_{i}\right)^{2}}\right]}{1-\left[1-A_{i}(\delta)\right]^{2}}-2 \sum_{i=1}^{n} \ln \left(1+x_{i}\right) \\
& +\sum_{i=1}^{n} \frac{A_{i}(\delta) \ln \left[\frac{\left(1+2 x_{i}\right)}{\left(1+x_{i}\right)^{2}}\right]}{1-A_{i}(\delta)}-2(1-\theta)(\theta+1) \sum_{i=1}^{n} \ln \frac{\left[1-A_{i}(\delta)\right] A_{i}(\delta) \ln \left[\frac{\left(1+2 x_{i}\right)}{\left(1+x_{i}\right)^{2}}\right]}{1-(1-\theta)\left[1-A_{i}(\delta)\right]^{2}} .
\end{aligned}
$$

These equations cannot be solved explicitly; hence, a nonlinear optimization algorithm such as the Newton Raphson method is used.

\subsection{Maximum Product Spacing}

According to Cheng and Amin [23], the maximum product spacing method is an efficient estimation method that has proved to have some advantages with respect to other point estimation methods. Thus, we use MPS in this section to have point estimation of the unknown parameters of the NEITL distribution. This can be obtained by solving equations resulted from taking partial derivatives of logarithm of product spacing function $G(\boldsymbol{\Omega})$ which is written as:

$$
G(\boldsymbol{\Omega})=\prod_{i=1}^{n+1}\left(\left[\frac{1-\left[1-A_{i-1}(\delta)\right]^{2}}{1-(1-\theta)\left[1-A_{i-1}(\delta)\right]^{2}}\right]^{\theta}-\left[\frac{1-\left[1-A_{i}(\delta)\right]^{2}}{1-(1-\theta)\left[1-A_{i}(\delta)\right]^{2}}\right]^{\theta}\right)^{\frac{1}{n+1}},
$$

and the logarithmic function of $G(\boldsymbol{\Omega})$

$$
\log G(\boldsymbol{\Omega})=\frac{1}{n+1} \sum_{i=1}^{n+1} \ln \left(\left[\frac{1-\left[1-A_{i-1}(\delta)\right]^{2}}{1-(1-\theta)\left[1-A_{i-1}(\delta)\right]^{2}}\right]^{\theta}-\left[\frac{1-\left[1-A_{i}(\delta)\right]^{2}}{1-(1-\theta)\left[1-A_{i}(\delta)\right]^{2}}\right]^{\theta}\right) \text {. }
$$

The MPS estimators of $\Omega$ are obtained by differentiating the log-product equation (Equation (29)) with respect to each parameter separately. We can solve the nonlinear system of equations by using any iterative technique, such as conjugate-gradient algorithms. Over the last few years, the estimation parameters of such models have been improved under censoring schemes-for instance, by Almetwally et al. [24] and El-Sherpieny et al. [25].

\subsection{Bayesian Estimation}

Bayesian method provide statistical inferences that are based on the prior distribution and loss function that are chosen. All parameters are treated as random variables with certain distributions, termed the prior distribution in this method. We must choose one if prior information is not available, which is frequently the case. The independent gamma distributions are our priors of choice because prior distribution selection plays such an essential role in parameter estimation. The joint prior distribution can be written as follows:

$$
\pi(\Omega) \propto \theta^{a_{1}-1} \delta^{a_{2}-1} e^{-\left(b_{1} \theta+b_{2} \delta\right)} .
$$

The joint posterior density function of $\Omega$ is obtained from (27) and (30):

$$
\pi(\Omega \mid \underline{x})=\frac{\ell(\underline{x} \mid \Omega) \cdot \pi(\Omega)}{\int_{\Omega} \ell(\underline{x} \mid \Omega) \cdot \pi(\Omega) d \Omega},
$$

where $\ell(\underline{x} \mid \Omega) \propto \theta^{2 n} \delta^{2 n} \prod_{i=1}^{n} \frac{\left(1+2 x_{i}\right)^{\delta-1}}{\left(1+x_{i}\right)^{2 \delta+1}}\left[1-A_{i}(\delta)\right] \frac{\left(1-\left[1-A_{i}(\delta)\right]^{2}\right)^{\theta-1}}{\left(1-(1-\theta)\left[1-A_{i}(\delta)\right]^{2}\right)^{\theta+1}}$. Then, the posterior NEITL distribution is 


$$
\pi(\Omega \mid \underline{x}) \propto \theta^{2 n+a_{1}-1} \delta^{2 n+a_{2}-1} e^{-\left(b_{1} \theta+b_{2} \delta\right)} \prod_{i=1}^{n} \frac{\left(1+2 x_{i}\right)^{\delta-1}}{\left(1+x_{i}\right)^{2 \delta+1}}\left[1-\frac{\left(1+2 x_{i}\right)^{\delta}}{\left(1+x_{i}\right)^{2 \delta}}\right] \frac{\left(1-\left[1-A_{i}(\delta)\right]^{2}\right)^{\theta-1}}{\left(1-(1-\theta)\left[1-A_{i}(\delta)\right]^{2}\right)^{\theta+1}}
$$

The conditional posterior distribution is as follows:

$$
\pi(\theta \mid \delta, \underline{x}) \propto \theta^{2 n+a_{1}-1} e^{-b_{1} \theta} \prod_{i=1}^{n} \frac{\left(1-\left[1-A_{i}(\delta)\right]^{2}\right)^{\theta-1}}{\left(1-(1-\theta)\left[1-A_{i}(\delta)\right]^{2}\right)^{\theta+1}}
$$

and

$$
\pi(\delta \mid \theta, \underline{x}) \propto \delta^{2 n+a_{2}-1} e^{-b_{2} \delta} \prod_{i=1}^{n} \frac{\left(1+2 x_{i}\right)^{\delta-1}}{\left(1+x_{i}\right)^{2 \delta+1}}\left[1-A_{i}(\delta)\right] \frac{\left(1-\left[1-A_{i}(\delta)\right]^{2}\right)^{\theta-1}}{\left(1-(1-\theta)\left[1-A_{i}(\delta)\right]^{2}\right)^{\theta+1}} .
$$

The loss function, on the other hand, is crucial in Bayesian approaches. The symmetric and asymmetric loss functions are used to create the majority of Bayesian inference processes. The Bayes estimators of $\Omega$, say, $\left(\widehat{\theta}_{B}, \widehat{\delta}_{B}\right)$, based on a squared error loss function, are given by

$$
\begin{aligned}
\hat{p}_{B-S E L}(\theta, \delta) & =E_{(\theta, \delta \underline{x})}[p(\theta, \delta)] \\
& =\int_{0}^{\infty} \int_{0}^{\infty} p(\theta, \delta) \times \pi(\Omega \mid \underline{x}) d \theta d \delta .
\end{aligned}
$$

It is noted that the integrals given by (35) cannot be obtained explicitly. Due to that, we used the Markov chain Monte Carlo technique (MCMC) to find approximate values of integrals (35). Many studies have used the MCMC technique, such as El-Sherpieny et al. [26], Almongy et al. [27], Haj Ahmad et al. [28], Bantan et al. [29], Almetwally et al. [24], AlOmari et al. [30], Al-Babtain et al. [31], and Hassan and Zaki [32].

\section{Simulation}

A simulation study has been conducted to examine the performances of point estimates in terms of their average estimates (AE), mean squared errors (MSE), interval estimates, and lengths of confidence interval (L.CI). The simulation study was carried out with various parameter values and sample sizes. This section is divided into two parts.

For the first reliability analysis: The parameters of the NEITL distribution were $(\theta ; \delta)=(0.5 ; 0.5)$ and $(0.5 ; 3)$ for the results in Table 2 and $(\theta ; \delta)=(3 ; 0.5)$ and $(3 ; 3)$ for the results in Table 3 . The sample sizes were $\mathrm{n}=30,80$, and 150 , respectively. We selected time (Q) to determine the HF and SF of the NEITL distribution where $R_{1}=S F(Q=0.25 ; \hat{\Omega})$, $R_{2}=S F(Q=0.35 ; \hat{\Omega}), H_{1}=H F(Q=0.25 ; \hat{\Omega})$, and $H_{2}=H F(Q=0.35 ; \hat{\Omega})$. The various simulation results are based on a total of 10,000 repetitions. The Bayes estimates are based on 10,000 samples and were derived using the MCMC approach. In Tables 2 and 3, the AE, MSEs, and L.CI of the various approaches are displayed.

Secondly, we estimated the reliability of the S-S model. The parameters of the NEITL distribution were $\left(\theta_{1} ; \delta_{1} ; \theta_{2} ; \delta_{2}\right)=(0.6 ; 0.75 ; 0.65 ; 2.5)$ is case 1 and $(0.6 ; 0.75 ; 2.65 ; 2.5)$-see Table 4 ; and $\left(\theta_{1} ; \delta_{1} ; \theta_{2} ; \delta_{2}\right)=(2 ; 1.75 ; 2.5 ; 2.5)$ is case 3 and $(0.6 ; 2.75 ; 2.65 ; 2.5)$ is case 4 - see Table 5 . The sample sizes of S-S model were $(n, m)=(25,30),(80,70)$, and $(150$, $120)$, respectively. 
Table 2. Accuracy measures for parameters of the NEITL distribution, and reliability analysis for different periods of time for $\theta=0.5$.

\begin{tabular}{|c|c|c|c|c|c|c|c|c|c|c|c|c|}
\hline \multicolumn{2}{|c|}{$\theta=0.5$} & & & \multicolumn{3}{|c|}{ MLE } & \multicolumn{3}{|c|}{ MPS } & \multicolumn{3}{|c|}{ Bayesian } \\
\hline$\delta$ & $\mathbf{n}$ & & & $\mathrm{AE}$ & MSE & L.CI & $\mathrm{AE}$ & MSE & L.CI & $\mathrm{AE}$ & MSE & L.CI \\
\hline \multirow{18}{*}{0.5} & \multirow{6}{*}{30} & & $\theta$ & 0.0875 & 0.2002 & 1.7121 & 0.0813 & 0.2001 & 1.7009 & 0.0419 & 0.0635 & 0.8738 \\
\hline & & & $\delta$ & 0.1646 & 0.2306 & 1.7411 & 0.0731 & 0.1905 & 1.6706 & 0.0400 & 0.0429 & 0.7872 \\
\hline & & \multirow{2}{*}{$Q=0.25$} & $R_{1}$ & 0.7500 & 0.0035 & 0.2262 & 0.7498 & 0.0032 & 0.2173 & 0.7359 & 0.0053 & 0.2714 \\
\hline & & & $H_{1}$ & 0.0043 & $1.29 \times 10^{-6}$ & 0.0039 & 0.0041 & $9.11 \times 10^{-7}$ & 0.0038 & 0.0042 & $1.49 \times 10^{-6}$ & 0.0048 \\
\hline & & \multirow{2}{*}{$\mathrm{Q}=0.35$} & $R_{2}$ & 0.6369 & 0.0051 & 0.2735 & 0.6489 & 0.0047 & 0.2651 & 0.6336 & 0.0078 & 0.3286 \\
\hline & & & $\mathrm{H}_{2}$ & 0.0021 & $2.11 \times 10^{-7}$ & 0.0016 & 0.0018 & $1.75 \times 10^{-7}$ & 0.0017 & 0.0021 & $3.09 \times 10^{-7}$ & 0.0021 \\
\hline & \multirow{6}{*}{80} & & $\theta$ & 0.1093 & 0.1784 & 1.6000 & 0.1621 & 0.1722 & 1.5607 & 0.0177 & 0.0215 & 0.5545 \\
\hline & & & $\delta$ & 0.0822 & 0.1284 & 1.3681 & 0.0518 & 0.1230 & 1.2400 & 0.0243 & 0.0203 & 0.5598 \\
\hline & & \multirow{2}{*}{$Q=0.25$} & $R_{1}$ & 0.7458 & 0.0011 & 0.1265 & 0.7494 & 0.0010 & 0.1258 & 0.7415 & 0.0014 & 0.1317 \\
\hline & & & $H_{1}$ & 0.0040 & $3.51 \times 10^{-7}$ & 0.0022 & 0.0039 & $3.13 \times 10^{-7}$ & 0.0021 & 0.0040 & $3.84 \times 10^{-7}$ & 0.0022 \\
\hline & & \multirow{2}{*}{$\mathrm{Q}=0.35$} & $R_{2}$ & 0.6423 & 0.0016 & 0.1526 & 0.6472 & 0.0015 & 0.1516 & 0.6392 & 0.0021 & 0.1612 \\
\hline & & & $\mathrm{H}_{2}$ & 0.0020 & $7.01 \times 10^{-8}$ & 0.0010 & 0.0019 & $6.27 \times 10^{-8}$ & 0.0010 & 0.0020 & $8.26 \times 10^{-8}$ & 0.0010 \\
\hline & \multirow{6}{*}{150} & & $\theta$ & 0.1014 & 0.1627 & 1.5310 & 0.1412 & 0.1521 & 1.4619 & 0.0038 & 0.0068 & 0.3083 \\
\hline & & & $\delta$ & 0.0627 & 0.0951 & 1.1839 & 0.0498 & 0.0910 & 1.1253 & 0.0103 & 0.0062 & 0.3008 \\
\hline & & \multirow{2}{*}{$Q=0.25$} & $R_{1}$ & 0.7472 & 0.0006 & 0.0966 & 0.7494 & 0.0006 & 0.0967 & 0.7469 & $6.11 \times 10^{-4}$ & 0.0940 \\
\hline & & & $H_{1}$ & 0.0040 & $2.06 \times 10^{-7}$ & 0.0016 & 0.0039 & $1.93 \times 10^{-7}$ & 0.0016 & 0.0039 & $1.61 \times 10^{-7}$ & 0.0016 \\
\hline & & \multirow{2}{*}{$\mathrm{Q}=0.35$} & $R_{2}$ & 0.6440 & 0.0009 & 0.1147 & 0.6468 & $8.65 \times 10^{-4}$ & 0.1146 & 0.6461 & $9.27 \times 10^{-4}$ & 0.1181 \\
\hline & & & $\mathrm{H}_{2}$ & 0.0020 & $4.39 \times 10^{-8}$ & 0.0008 & 0.0019 & $4.07 \times 10^{-8}$ & 0.0008 & 0.0019 & $3.49 \times 10^{-8}$ & 0.0007 \\
\hline \multirow{18}{*}{3} & \multirow{6}{*}{25} & & $\theta$ & 0.0128 & 0.2007 & 1.7037 & 0.0140 & 0.0135 & 0.4524 & 0.0197 & 0.0086 & 0.3640 \\
\hline & & & $\delta$ & -0.0015 & 0.2298 & 1.7140 & -0.0693 & 0.1306 & 1.3911 & -0.0178 & 0.0681 & 1.0029 \\
\hline & & \multirow{2}{*}{$\mathrm{Q}=0.25$} & $R_{1}$ & 0.7429 & 0.0032 & 0.2212 & 0.7535 & 0.0030 & 0.2148 & 0.7390 & 0.0037 & 0.2296 \\
\hline & & & $H_{1}$ & 0.2805 & 0.0043 & 0.2533 & 0.2671 & 0.0038 & 0.2412 & 0.2841 & 0.0049 & 0.2588 \\
\hline & & \multirow{2}{*}{$\mathrm{Q}=0.35$} & $R_{2}$ & 0.6427 & 0.0047 & 0.2688 & 0.6562 & 0.0045 & 0.2625 & 0.6384 & 0.0054 & 0.2772 \\
\hline & & & $\mathrm{H}_{2}$ & 0.2851 & 0.0036 & 0.2344 & 0.2722 & 0.0033 & 0.2234 & 0.2882 & 0.0042 & 0.2387 \\
\hline & \multirow{6}{*}{80} & & $\theta$ & 0.0233 & 0.0136 & 0.4482 & 0.0007 & 0.0029 & 0.2101 & 0.0067 & 0.0028 & 0.2001 \\
\hline & & & $\delta$ & -0.0012 & 0.1313 & 1.2926 & -0.0189 & 0.0360 & 0.7405 & -0.0068 & 0.0308 & 0.6843 \\
\hline & & \multirow{2}{*}{$\mathrm{Q}=0.25$} & $R_{1}$ & 0.7475 & 0.0009 & 0.1203 & 0.7529 & 0.0009 & 0.1185 & 0.7466 & 0.0011 & 0.1252 \\
\hline & & & $H_{1}$ & 0.2740 & 0.0012 & 0.1339 & 0.2673 & 0.0011 & 0.1318 & 0.2745 & 0.0014 & 0.1406 \\
\hline & & \multirow{2}{*}{$\mathrm{Q}=0.35$} & $R_{2}$ & 0.6473 & 0.0014 & 0.1464 & 0.6542 & 0.0014 & 0.1457 & 0.6464 & 0.0016 & 0.1538 \\
\hline & & & $\mathrm{H}_{2}$ & 0.2791 & 0.0010 & 0.1257 & 0.2732 & 0.0010 & 0.1228 & 0.2800 & 0.0012 & 0.1319 \\
\hline & \multirow{6}{*}{150} & & $\theta$ & 0.0034 & 0.0035 & 0.2332 & -0.0017 & 0.0018 & 0.1679 & 0.0032 & 0.0016 & 0.1496 \\
\hline & & & $\delta$ & 0.0063 & 0.0746 & 1.0707 & -0.0065 & 0.0224 & 0.5869 & -0.0042 & 0.0150 & 0.4773 \\
\hline & & \multirow{2}{*}{$Q=0.25$} & $R_{1}$ & 0.7494 & 0.0006 & 0.0971 & 0.7528 & 0.0006 & 0.0961 & 0.7484 & 0.0007 & 0.0962 \\
\hline & & & $H_{1}$ & 0.2716 & 0.0008 & 0.1083 & 0.2675 & 0.0008 & 0.1069 & 0.2724 & 0.0009 & 0.1075 \\
\hline & & \multirow{2}{*}{$\mathrm{Q}=0.35$} & $R_{2}$ & 0.6495 & 0.0009 & 0.1189 & 0.6538 & 0.0009 & 0.1182 & 0.6484 & 0.0010 & 0.1185 \\
\hline & & & $\mathrm{H}_{2}$ & 0.2774 & 0.0007 & 0.1012 & 0.2736 & 0.0007 & 0.0996 & 0.2782 & 0.0008 & 0.1013 \\
\hline
\end{tabular}


Table 3. Accuracy measures for parameters of the NEITL distribution, and reliability analysis for different periods of time for $\theta=3$.

\begin{tabular}{|c|c|c|c|c|c|c|c|c|c|c|c|c|}
\hline \multicolumn{2}{|c|}{$\theta=3$} & & & \multicolumn{3}{|c|}{ MLE } & \multicolumn{3}{|c|}{ MPS } & \multicolumn{3}{|c|}{ Bayesian } \\
\hline$\delta$ & $\mathbf{n}$ & & & $\mathrm{AE}$ & MSE & L.CI & $\mathrm{AE}$ & MSE & L.CI & $\mathrm{AE}$ & MSE & L.CI \\
\hline \multirow{18}{*}{0.5} & \multirow{6}{*}{30} & & $\theta$ & 0.0044 & 0.4520 & 2.6372 & -0.3054 & 0.4210 & 2.2450 & -0.0197 & 0.0670 & 0.9916 \\
\hline & & & $\delta$ & 0.0215 & 0.1230 & 1.3740 & 0.1181 & 0.0898 & 1.0801 & 0.0240 & 0.0115 & 0.3713 \\
\hline & & \multirow{2}{*}{$Q=0.25$} & $R_{1}$ & 0.7461 & 0.0038 & 0.2451 & 0.7479 & 0.0033 & 0.2276 & 0.7375 & 0.0046 & 0.2388 \\
\hline & & & $H_{1}$ & 0.4116 & 0.0115 & 0.4159 & 0.4015 & 0.0097 & 0.3852 & 0.4261 & 0.0140 & 0.4222 \\
\hline & & \multirow{2}{*}{$\mathrm{Q}=0.35$} & $R_{2}$ & 0.6466 & 0.0056 & 0.2970 & 0.6508 & 0.0051 & 0.2775 & 0.6367 & 0.0065 & 0.2943 \\
\hline & & & $\mathrm{H}_{2}$ & 0.4372 & 0.0112 & 0.4083 & 0.4220 & 0.0095 & 0.3776 & 0.4495 & 0.0138 & 0.4233 \\
\hline & \multirow{6}{*}{80} & & $\theta$ & -0.0571 & 0.2683 & 2.0189 & -0.1001 & 0.0945 & 1.1397 & -0.0118 & 0.0279 & 0.6472 \\
\hline & & & $\delta$ & 0.0404 & 0.0381 & 0.7487 & 0.0270 & 0.0103 & 0.3833 & 0.0098 & 0.0029 & 0.2039 \\
\hline & & \multirow{2}{*}{$\mathrm{Q}=0.25$} & $R_{1}$ & 0.7470 & 0.0010 & 0.1241 & 0.7505 & 0.0009 & 0.1192 & 0.7455 & 0.0011 & 0.1232 \\
\hline & & & $H_{1}$ & 0.4056 & 0.0028 & 0.2067 & 0.3995 & 0.0027 & 0.2031 & 0.4099 & 0.0033 & 0.2120 \\
\hline & & \multirow{2}{*}{$Q=0.35$} & $R_{2}$ & 0.6472 & 0.0015 & 0.1515 & 0.6517 & 0.0014 & 0.1477 & 0.6449 & 0.0017 & 0.1532 \\
\hline & & & $\mathrm{H}_{2}$ & 0.4296 & 0.0027 & 0.2046 & 0.4232 & 0.0027 & 0.2019 & 0.4345 & 0.0033 & 0.2125 \\
\hline & \multirow{6}{*}{150} & & $\theta$ & 0.0134 & 0.0735 & 1.0617 & -0.0557 & 0.0382 & 0.7353 & -0.0086 & 0.0117 & 0.4165 \\
\hline & & & $\delta$ & 0.0038 & 0.0044 & 0.2605 & 0.0118 & 0.0028 & 0.2036 & 0.0040 & 0.0014 & 0.1387 \\
\hline & & \multirow{2}{*}{$Q=0.25$} & $R_{1}$ & 0.7493 & 0.0005 & 0.0885 & 0.7510 & 0.0005 & 0.0877 & 0.7486 & 0.0006 & 0.0927 \\
\hline & & & $H_{1}$ & 0.4029 & 0.0015 & 0.1520 & 0.3993 & 0.0015 & 0.1506 & 0.4042 & 0.0017 & 0.1597 \\
\hline & & \multirow{2}{*}{$\mathrm{Q}=0.35$} & $R_{2}$ & 0.6494 & 0.0008 & 0.1103 & 0.6518 & 0.0008 & 0.1095 & 0.6486 & 0.0009 & 0.1161 \\
\hline & & & $\mathrm{H}_{2}$ & 0.4279 & 0.0015 & 0.1521 & 0.4237 & 0.0015 & 0.1506 & 0.4290 & 0.0017 & 0.1601 \\
\hline \multirow{18}{*}{3} & \multirow{6}{*}{25} & & $\theta$ & 0.7823 & 3.2109 & 6.3225 & -0.1464 & 0.3771 & 2.3388 & -0.0035 & 0.0587 & 0.9477 \\
\hline & & & $\delta$ & 0.0619 & 3.2238 & 7.0377 & 0.2793 & 0.6266 & 2.9050 & -0.0072 & 0.0667 & 1.0296 \\
\hline & & \multirow{2}{*}{$Q=0.25$} & $R_{1}$ & 0.7490 & 0.0031 & 0.2172 & 0.7527 & 0.0026 & 0.1984 & 0.7515 & 0.0017 & 0.1578 \\
\hline & & & $H_{1}$ & 2.3694 & 0.3144 & 2.1952 & 2.3050 & 0.2756 & 2.0555 & 2.3288 & 0.1847 & 1.6417 \\
\hline & & \multirow{2}{*}{$\mathrm{Q}=0.35$} & $R_{2}$ & 0.6495 & 0.0046 & 0.2665 & 0.6554 & 0.0040 & 0.2485 & 0.6528 & 0.0027 & 0.2000 \\
\hline & & & $\mathrm{H}_{2}$ & 2.8692 & 0.4192 & 2.5313 & 2.7668 & 0.3667 & 2.3667 & 2.8072 & 0.2489 & 1.9051 \\
\hline & \multirow{6}{*}{80} & & $\theta$ & 0.3595 & 1.3131 & 4.2674 & -0.0903 & 0.1382 & 1.4145 & -0.0080 & 0.0269 & 0.6306 \\
\hline & & & $\delta$ & 0.0021 & 1.2808 & 4.4386 & 0.1369 & 0.2231 & 1.7731 & -0.0052 & 0.0276 & 0.6449 \\
\hline & & \multirow{2}{*}{$Q=0.25$} & $R_{1}$ & 0.7513 & 0.0010 & 0.1262 & 0.7519 & 0.0008 & 0.1126 & 0.7519 & 0.0007 & 0.0992 \\
\hline & & & $H_{1}$ & 2.3306 & 0.0959 & 1.2146 & 2.3116 & 0.0863 & 1.1484 & 2.3194 & 0.0739 & 1.0318 \\
\hline & & \multirow{2}{*}{$\mathrm{Q}=0.35$} & $R_{2}$ & 0.6518 & 0.0016 & 0.1545 & 0.6532 & 0.0013 & 0.1420 & 0.6528 & 0.0011 & 0.1260 \\
\hline & & & $\mathrm{H}_{2}$ & 2.8178 & 0.1231 & 1.3759 & 2.7823 & 0.1157 & 1.3265 & 2.7978 & 0.1002 & 1.2029 \\
\hline & \multirow{6}{*}{150} & & $\theta$ & 0.2715 & 0.9255 & 3.6196 & -0.0411 & 0.0771 & 1.0772 & -0.0064 & 0.0098 & 0.3843 \\
\hline & & & $\delta$ & 0.0304 & 1.1950 & 4.2856 & 0.0627 & 0.1185 & 1.3276 & -0.0006 & 0.0108 & 0.3920 \\
\hline & & \multirow{2}{*}{$\mathrm{Q}=0.25$} & $R_{1}$ & 0.7514 & 0.0006 & 0.0982 & 0.7515 & 0.0004 & 0.0829 & 0.7510 & 0.0003 & 0.0653 \\
\hline & & & $H_{1}$ & 2.3255 & 0.0533 & 0.9045 & 2.3185 & 0.0465 & 0.8429 & 2.3267 & 0.0303 & 0.6728 \\
\hline & & \multirow{2}{*}{$\mathrm{Q}=0.35$} & $R_{2}$ & 0.6519 & 0.0009 & 0.1180 & 0.6523 & 0.0007 & 0.1044 & 0.6514 & 0.0005 & 0.0825 \\
\hline & & & $\mathrm{H}_{2}$ & 2.8103 & 0.0657 & 1.0047 & 2.7942 & 0.0620 & 0.9720 & 2.8067 & 0.0409 & 0.7801 \\
\hline
\end{tabular}


Table 4. Accuracy measures for parameters of the NEITL distribution, and reliability analysis for different periods of time for case 1 and case 2 .

\begin{tabular}{|c|c|c|c|c|c|c|c|c|c|c|c|}
\hline \multirow[t]{2}{*}{ Case } & \multirow[b]{2}{*}{$\mathrm{n}, \mathrm{m}$} & & \multicolumn{3}{|c|}{ MLE } & \multicolumn{3}{|c|}{ MPS } & \multicolumn{3}{|c|}{ Bayesian } \\
\hline & & & $\mathrm{AE}$ & MSE & L.CI & $\mathrm{AE}$ & MSE & L.CI & $\mathrm{AE}$ & MSE & L.CI \\
\hline \multirow{15}{*}{1} & \multirow{5}{*}{25,30} & $\theta_{1}$ & 0.0616 & 0.1473 & 1.4864 & 0.1520 & 0.1840 & 1.5742 & 0.0335 & 0.0437 & 0.7637 \\
\hline & & $\delta_{1}$ & 0.1833 & 0.3414 & 2.1768 & 0.0562 & 0.2808 & 2.0675 & 0.0211 & 0.0481 & 0.8245 \\
\hline & & $\theta_{2}$ & 0.0443 & 0.0724 & 1.0414 & 0.0726 & 0.0649 & 0.9579 & 0.0079 & 0.0134 & 0.4490 \\
\hline & & $\delta_{2}$ & 0.1103 & 0.7321 & 3.3293 & -0.1033 & 0.5550 & 2.8949 & -0.0034 & 0.0622 & 0.9261 \\
\hline & & $\mathrm{R}$ & 0.8257 & 0.0008 & 0.1057 & 0.8188 & 0.0009 & 0.1048 & 0.8198 & 0.0026 & 0.1168 \\
\hline & \multirow{5}{*}{80,70} & $\theta_{1}$ & 0.0510 & 0.1108 & 1.2910 & 0.0995 & 0.1361 & 1.3942 & 0.0248 & 0.0156 & 0.4902 \\
\hline & & $\delta_{1}$ & 0.1207 & 0.2031 & 1.7038 & 0.0646 & 0.1908 & 1.6953 & 0.0008 & 0.0223 & 0.5705 \\
\hline & & $\theta_{2}$ & 0.0097 & 0.0211 & 0.5689 & 0.0351 & 0.0307 & 0.6739 & 0.0091 & 0.0053 & 0.2729 \\
\hline & & $\delta_{2}$ & 0.0776 & 0.2878 & 2.0828 & -0.0305 & 0.3172 & 2.2068 & -0.0074 & 0.0334 & 0.7208 \\
\hline & & $\mathrm{R}$ & 0.8316 & 0.0003 & 0.0692 & 0.8281 & 0.0003 & 0.0697 & 0.8300 & 0.0003 & 0.0694 \\
\hline & \multirow{5}{*}{150,120} & $\theta_{1}$ & 0.0364 & 0.0790 & 1.0937 & 0.0613 & 0.0888 & 1.1441 & 0.0034 & 0.0051 & 0.2641 \\
\hline & & $\delta_{1}$ & 0.0905 & 0.1390 & 1.4189 & 0.0609 & 0.1388 & 1.4424 & 0.0072 & 0.0071 & 0.3124 \\
\hline & & $\theta_{2}$ & 0.0146 & 0.0185 & 0.5302 & 0.0266 & 0.0235 & 0.5929 & 0.0011 & 0.0024 & 0.1825 \\
\hline & & $\delta_{2}$ & 0.0424 & 0.2233 & 1.8467 & -0.0125 & 0.2486 & 1.9558 & 0.0088 & 0.0104 & 0.4007 \\
\hline & & $\mathrm{R}$ & 0.8333 & 0.0002 & 0.0528 & 0.8310 & 0.0002 & 0.0534 & 0.8319 & 0.0002 & 0.0459 \\
\hline \multirow{15}{*}{2} & \multirow{5}{*}{25,30} & $\theta_{1}$ & 0.0439 & 0.1438 & 1.4778 & 0.1211 & 0.1711 & 1.5518 & 0.0366 & 0.0404 & 0.7013 \\
\hline & & $\delta_{1}$ & 0.1944 & 0.3157 & 2.0686 & 0.0782 & 0.2577 & 1.9680 & 0.0241 & 0.0491 & 0.8161 \\
\hline & & $\theta_{2}$ & 0.2202 & 0.5042 & 2.6489 & -0.1283 & 0.2027 & 1.6934 & -0.0028 & 0.0540 & 0.8770 \\
\hline & & $\delta_{2}$ & -0.0569 & 0.4444 & 2.6064 & 0.1952 & 0.3302 & 2.1209 & 0.0008 & 0.0512 & 0.8629 \\
\hline & & $\mathrm{R}$ & 0.9413 & 0.0006 & 0.0964 & 0.9350 & 0.0009 & 0.1055 & 0.9419 & 0.0014 & 0.0843 \\
\hline & \multirow{5}{*}{80,70} & $\theta_{1}$ & 0.0483 & 0.1344 & 1.4775 & 0.1200 & 0.1689 & 1.5422 & 0.0326 & 0.0373 & 0.6871 \\
\hline & & $\delta_{1}$ & 0.1839 & 0.3006 & 2.0270 & 0.0759 & 0.2500 & 1.9394 & 0.0248 & 0.0469 & 0.8096 \\
\hline & & $\theta_{2}$ & 0.2154 & 0.4842 & 2.5963 & -0.1161 & 0.1949 & 1.6714 & -0.0023 & 0.0509 & 0.8596 \\
\hline & & $\delta_{2}$ & -0.0524 & 0.4238 & 2.5462 & 0.1866 & 0.3088 & 2.0538 & 0.0008 & 0.0469 & 0.8333 \\
\hline & & $\mathrm{R}$ & 0.9420 & 0.0006 & 0.0915 & 0.9362 & 0.0008 & 0.0996 & 0.9423 & 0.0013 & 0.0827 \\
\hline & \multirow{5}{*}{150,120} & $\theta_{1}$ & 0.0203 & 0.0837 & 1.1326 & 0.0384 & 0.0833 & 1.1222 & 0.0276 & 0.0364 & 0.6734 \\
\hline & & $\delta_{1}$ & 0.1220 & 0.1737 & 1.5636 & 0.0861 & 0.1475 & 1.4688 & 0.0382 & 0.0469 & 0.8254 \\
\hline & & $\theta_{2}$ & 0.0302 & 0.0668 & 1.0074 & -0.1569 & 0.2685 & 1.9378 & 0.0046 & 0.0487 & 0.8573 \\
\hline & & $\delta_{2}$ & -0.0076 & 0.0753 & 1.0761 & 0.2513 & 0.4349 & 2.3923 & -0.0051 & 0.0533 & 0.8637 \\
\hline & & $\mathrm{R}$ & 0.9456 & 0.0001 & 0.0351 & 0.9436 & 0.0001 & 0.0364 & 0.9495 & 0.0001 & 0.0314 \\
\hline
\end{tabular}

Tables $2-5$ present the results, which highlight some interesting facts. As the sample size gets larger, the estimates get more accurate, demonstrating that they are asymptotically unbiased. Furthermore, the MSE decreases as the sample size increases in all cases, demonstrating that the various estimates are consistent. When comparing the various estimates, we can observe that in the majority of cases, the Bayes estimates have the lowest MSE. MPS estimate is a good alternative for ML estimate (MLE). The L-CI for the estimates approach zero as the sample size (n) increases, indicating that the $\mathrm{CI}$ for the largest sample size is the shortest CI. The greater the time we tested $(Q)$, the lower the HF and SF values. When estimating the reliability of the $S-S$ model in most cases, we received large values close to one, which indicates the quality of the model used. 
Table 5. Accuracy measures for parameters of the NEITL distribution, and reliability analysis for different periods of time for case 3 and case 4 .

\begin{tabular}{|c|c|c|c|c|c|c|c|c|c|c|c|}
\hline \multirow[t]{2}{*}{ Case } & \multirow[b]{2}{*}{$\mathrm{n}, \mathrm{m}$} & & \multicolumn{3}{|c|}{ MLE } & \multicolumn{3}{|c|}{ MPS } & \multicolumn{3}{|c|}{ Bayesian } \\
\hline & & & $\mathrm{AE}$ & MSE & L.CI & $\mathrm{AE}$ & MSE & L.CI & $\mathrm{AE}$ & MSE & L.CI \\
\hline \multirow{15}{*}{3} & \multirow{5}{*}{25,30} & $\theta_{1}$ & 0.7656 & 3.1827 & 6.3231 & 0.0110 & 0.7518 & 3.4021 & 0.0212 & 0.0454 & 0.8269 \\
\hline & & $\delta_{1}$ & 0.1439 & 1.7960 & 5.2283 & 0.2880 & 0.7248 & 3.1438 & -0.0114 & 0.0521 & 0.8734 \\
\hline & & $\theta_{2}$ & 0.9499 & 4.4971 & 7.4397 & -0.0677 & 0.5883 & 2.9978 & 0.0097 & 0.0520 & 0.8664 \\
\hline & & $\delta_{2}$ & 0.1369 & 3.2851 & 7.0917 & 0.3426 & 1.0036 & 3.6939 & -0.0015 & 0.0648 & 0.9911 \\
\hline & & $\mathrm{R}$ & 0.7228 & 0.0037 & 0.2406 & 0.7202 & 0.0036 & 0.2337 & 0.7198 & 0.0034 & 0.2146 \\
\hline & \multirow{5}{*}{80,70} & $\theta_{1}$ & 0.3765 & 1.3337 & 4.2840 & 0.0197 & 0.3368 & 2.2759 & 0.0025 & 0.0171 & 0.4865 \\
\hline & & $\delta_{1}$ & 0.0930 & 0.9049 & 3.7147 & 0.1322 & 0.3505 & 2.2643 & 0.0035 & 0.0202 & 0.5197 \\
\hline & & $\theta_{2}$ & 0.3805 & 1.4584 & 4.4973 & -0.0547 & 0.3464 & 2.2996 & 0.0025 & 0.0249 & 0.6042 \\
\hline & & $\delta_{2}$ & 0.0725 & 1.2650 & 4.4042 & 0.2302 & 0.5551 & 2.7805 & -0.0022 & 0.0294 & 0.6962 \\
\hline & & $\mathrm{R}$ & 0.7256 & 0.0013 & 0.1402 & 0.7219 & 0.0012 & 0.1354 & 0.7202 & 0.0013 & 0.1402 \\
\hline & \multirow{5}{*}{150,120} & $\theta_{1}$ & 0.2757 & 0.9253 & 3.6162 & 0.0430 & 0.2072 & 1.7780 & 0.0036 & 0.0088 & 0.3603 \\
\hline & & $\delta_{1}$ & 0.0914 & 0.7308 & 3.3352 & 0.0487 & 0.1931 & 1.7136 & -0.0055 & 0.0083 & 0.3559 \\
\hline & & $\theta_{2}$ & 0.3190 & 1.1487 & 4.0149 & -0.0215 & 0.2164 & 1.8236 & 0.0057 & 0.0095 & 0.3781 \\
\hline & & $\delta_{2}$ & 0.0404 & 1.0387 & 3.9961 & 0.1224 & 0.3149 & 2.1490 & -0.0092 & 0.0106 & 0.4029 \\
\hline & & $\mathrm{R}$ & 0.7243 & 0.0008 & 0.1076 & 0.7217 & 0.0007 & 0.1031 & 0.7218 & 0.0006 & 0.0964 \\
\hline \multirow{15}{*}{4} & \multirow{5}{*}{25,30} & $\theta_{1}$ & 0.0873 & 0.1165 & 1.2946 & 0.1136 & 0.1002 & 1.1594 & 0.0204 & 0.0163 & 0.4498 \\
\hline & & $\delta_{1}$ & 0.0713 & 1.1009 & 4.1077 & -0.1877 & 0.8136 & 3.4619 & -0.0133 & 0.0745 & 0.9809 \\
\hline & & $\theta_{2}$ & 0.5909 & 2.0654 & 5.1406 & -0.0731 & 0.4676 & 2.6679 & -0.0043 & 0.0520 & 0.8618 \\
\hline & & $\delta_{2}$ & -0.0785 & 1.3511 & 4.5506 & 0.2558 & 0.6836 & 3.0852 & 0.0041 & 0.0580 & 0.9599 \\
\hline & & $\mathrm{R}$ & 0.9248 & 0.0005 & 0.0878 & 0.9246 & 0.0005 & 0.0888 & 0.9207 & 0.0009 & 0.0962 \\
\hline & \multirow{5}{*}{80,70} & $\theta_{1}$ & 0.0788 & 0.0696 & 0.9878 & 0.0535 & 0.0363 & 0.7175 & 0.0081 & 0.0040 & 0.2443 \\
\hline & & $\delta_{1}$ & -0.0753 & 0.6112 & 3.0534 & -0.1039 & 0.3955 & 2.4339 & -0.0091 & 0.0302 & 0.6873 \\
\hline & & $\theta_{2}$ & 0.2045 & 0.5337 & 2.7519 & -0.0618 & 0.2220 & 1.8330 & -0.0037 & 0.0227 & 0.5760 \\
\hline & & $\delta_{2}$ & -0.0210 & 0.4744 & 2.7013 & 0.1593 & 0.3110 & 2.0972 & -0.0036 & 0.0235 & 0.5869 \\
\hline & & $\mathrm{R}$ & 0.9266 & 0.0002 & 0.0554 & 0.9259 & 0.0002 & 0.0557 & 0.9245 & 0.0002 & 0.0552 \\
\hline & \multirow{5}{*}{150,120} & $\theta_{1}$ & 0.0477 & 0.0317 & 0.6736 & 0.0271 & 0.0158 & 0.4820 & 0.0040 & 0.0020 & 0.1743 \\
\hline & & $\delta_{1}$ & -0.0626 & 0.3421 & 2.2817 & -0.0505 & 0.2179 & 1.8211 & 0.0010 & 0.0113 & 0.4141 \\
\hline & & $\theta_{2}$ & 0.0683 & 0.2062 & 1.7614 & -0.0761 & 0.1350 & 1.4107 & 0.0043 & 0.0095 & 0.3757 \\
\hline & & $\delta_{2}$ & 0.0123 & 0.2282 & 1.8738 & 0.1348 & 0.1905 & 1.6290 & -0.0017 & 0.0111 & 0.4077 \\
\hline & & $\mathrm{R}$ & 0.9260 & 0.0001 & 0.0419 & 0.9257 & 0.0001 & 0.0421 & 0.9258 & 0.0001 & 0.0395 \\
\hline
\end{tabular}

\section{Application of Real Data}

To demonstrate the NEITL model's flexibility and applicability in practice, two real life datasets are analyzed in this section. The NEITL distribution is compared to the ITL, exponentiated Lomax (EL), exponentiated exponential (ExEx), Weibull (W), Kumaraswamy Weibull (KW), modified Kies ITL (MKITL), and odd Weibull ITL (OWITL) distributions for the first batch of data. The NEITL distribution is compared to the ITL, EL, ExEx, W, KW, Kumaraswamy ITL (KIT), MKITL, and OWITL distributions for the second dataset. The approach of maximum likelihood was used to estimate the unknown parameters of the specified models for the two real datasets. To compare all of the models, the following statistics are used: Kolmogorov-Smirnov (KS), Cramer-von Mises (CVM), AndersonDarling (AD), Akaike information criterion (AIC), and Bayesian information criterion (BIC). 


\subsection{Survival Times}

Bjerkedal [33] observed and reported the survival periods (in days) of 72 guinea pigs infected with virulent tubercle bacilli in the first dataset. These data are as follows: 0.1 , $0.33,0.44,0.56,0.59,0.59,0.72,0.74,0.92,0.93,0.96,1,1,1.02,1.05,1.07,1.07,1.08,1.08,1.08$, $1.09,1.12,1.13,1.15,1.16,1.2,1.21,1.22,1.22,1.24,1.3,1.34,1.36,1.39,1.44,1.46,1.53,1.59$, $1.6,1.63,1.63,1.68,1.71,1.72,1.76,1.83,1.95,1.96,1.97,2.02,2.13,2.15,2.16,2.22,2.3,2.31$, $2.4,2.45,2.51,2.53,2.54,2.54,2.78,2.93,3.27,3.42,3.47,3.61,4.02,4.32,4.58$, and 5.55.

MLEs, SE, KS, CVM, AD, AIC, and BIC values for the first dataset are summarized in Table 6. The NEITL model has the least values for the statistical measures among all fitted models, as shown in the table.

As a result, the NEITL model might be the best option. Figure 6 shows the estimated CDF, estimated PDF, and PP plot of the fitted NEITL model, respectively.
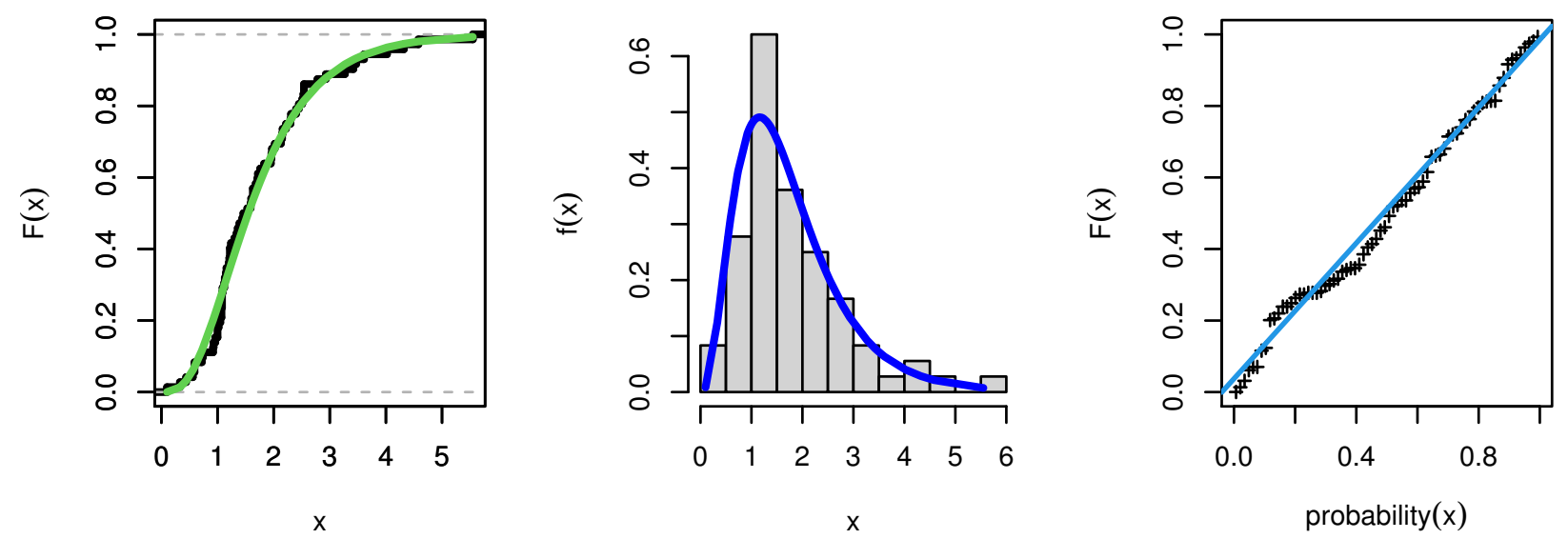

Figure 6. PDF, CDF, and PP plot of the NEITL distribution:Survival Times.

Table 6. MLE with SE and other metrics: Survival Times.

\begin{tabular}{|c|c|c|c|c|c|c|c|c|}
\hline & & Estimation & SE & KS & CVM & $\mathrm{AD}$ & AIC & BIC \\
\hline ITL & $\delta$ & 2.0225 & 0.2384 & 0.2989 & 0.0942 & 0.6663 & 229.6917 & 231.9684 \\
\hline \multirow{2}{*}{ NEITL } & $\theta$ & 60.9983 & 19.8002 & \multirow{2}{*}{0.0902} & \multirow{2}{*}{0.0776} & \multirow{2}{*}{0.4946} & \multirow{2}{*}{193.1635} & \multirow{2}{*}{197.7168} \\
\hline & $\delta$ & 0.0299 & 0.0549 & & & & & \\
\hline \multirow{3}{*}{ EL } & $\alpha$ & 3.7415 & 0.8152 & \multirow{3}{*}{0.0978} & \multirow{3}{*}{0.0766} & \multirow{3}{*}{0.4949} & \multirow{3}{*}{195.2402} & \multirow{3}{*}{202.0702} \\
\hline & $\beta$ & 37.0309 & 60.7818 & & & & & \\
\hline & $\lambda$ & 31.2893 & 54.2759 & & & & & \\
\hline \multirow{2}{*}{ ExEx } & $\alpha$ & 15.4717 & 20.7674 & \multirow{2}{*}{0.2194} & \multirow{2}{*}{0.2209} & \multirow{2}{*}{1.2910} & \multirow{2}{*}{210.8807} & \multirow{2}{*}{215.4340} \\
\hline & $\beta$ & 0.0240 & 0.0334 & & & & & \\
\hline \multirow{2}{*}{ W } & $\alpha$ & 1.8173 & 0.1583 & \multirow{2}{*}{0.7439} & \multirow{2}{*}{0.0865} & \multirow{2}{*}{0.5852} & \multirow{2}{*}{195.8812} & \multirow{2}{*}{200.4345} \\
\hline & $\beta$ & 0.2856 & 0.0544 & & & & & \\
\hline \multirow{4}{*}{ KW } & $\alpha$ & 0.7474 & 0.6138 & \multirow{4}{*}{0.0917} & \multirow{4}{*}{0.0878} & \multirow{4}{*}{0.5351} & \multirow{4}{*}{196.6326} & \multirow{4}{*}{205.7393} \\
\hline & $\beta$ & 0.9899 & 1.0882 & & & & & \\
\hline & $\lambda$ & 3.0474 & 3.9283 & & & & & \\
\hline & $\theta$ & 1.7871 & 6.0095 & & & & & \\
\hline \multirow{2}{*}{ MKITL } & $\alpha$ & 1.4212 & 0.1359 & \multirow{2}{*}{0.1015} & \multirow{2}{*}{0.1272} & \multirow{2}{*}{0.7577} & \multirow{2}{*}{194.5589} & 1001120 \\
\hline & $\beta$ & 1.1937 & 0.0725 & & & & & 199.1122 \\
\hline & $\alpha$ & 1.8048 & 0.2146 & & & & & \\
\hline OWITL & $\beta$ & 25.9044 & 64.9941 & 0.0969 & 0.0873 & 0.5415 & 195.0995 & 201.9295 \\
\hline & $\lambda$ & 0.2721 & 0.3106 & & & & & \\
\hline
\end{tabular}




\subsection{Example of Reliability of the S-S Model}

Nelson [34] (Ch. 10, Table 4.1) calculated the time it takes for an insulating fluid to break down under high voltage stress in minutes. The failure times were observed in groups of ten insulating fluids, with each group reporting data on ten of them. Consider the following two sets of failure time data samples presented as follows for the purpose of showing the methods of inference outlined in the preceding sections:

Group 1: $0.31,0.66,1.54,1.70,1.82,1.89,2.17,2.24,4.03$, and 9.99 .

Group 2: $0.49,0.64,0.82,0.93,1.08,1.99,2.06,2.15,2.57$, and 4.75 .

MLEs, SE, KS, CVM, AD, AIC, and BIC values for the data of Group 1 and Group 2 are summarized in Tables 7 and 8 . The NEITL model resulted in the best values for the statistical measures among all fitted models, as shown in theses tables. Table 9 provided MLE, MPS, and Bayesian estimates for reliability of the S-S model.

As a result, the NEITL model might be the best option. Figures 7 and 8 show the estimated CDFs, estimated PDFs, and PP plot of the fitted NEITL model, respectively.

Table 7. MLE with SE and other metrics: Group 1.

\begin{tabular}{|c|c|c|c|c|c|c|c|c|}
\hline & & Estimation & SE & KS & CVM & AD & AIC & BIC \\
\hline ITL & $\delta$ & 1.5750 & 0.4981 & 0.3141 & 0.0984 & 0.5089 & 41.4301 & 41.7327 \\
\hline \multirow{2}{*}{ NEITL } & $\theta$ & 0.4244 & 0.4225 & \multirow{2}{*}{0.2129} & \multirow{2}{*}{0.0924} & \multirow{2}{*}{0.4806} & \multirow{2}{*}{41.4921} & \multirow{2}{*}{42.0973} \\
\hline & $\delta$ & 5.6463 & 5.1060 & & & & & \\
\hline \multirow{3}{*}{ EL } & $\alpha$ & 2.6559 & 2.0932 & \multirow{3}{*}{0.2181} & \multirow{3}{*}{0.0928} & \multirow{3}{*}{0.4831} & \multirow{3}{*}{43.5499} & \multirow{3}{*}{44.4577} \\
\hline & $\beta$ & 3.4714 & 4.0843 & & & & & \\
\hline & $\lambda$ & 3.4753 & 6.7246 & & & & & \\
\hline \multirow{2}{*}{ ExEx } & $\alpha$ & 1.0925 & 0.7304 & \multirow{2}{*}{0.2348} & \multirow{2}{*}{0.1133} & \multirow{2}{*}{0.6265} & \multirow{2}{*}{43.3593} & \multirow{2}{*}{43.9644} \\
\hline & $\beta$ & 0.3309 & 0.3558 & & & & & \\
\hline \multirow{2}{*}{ W } & $\alpha$ & 1.1585 & 0.2641 & \multirow{2}{*}{0.5557} & \multirow{2}{*}{0.0968} & \multirow{2}{*}{0.5082} & \multirow{2}{*}{42.9958} & \multirow{2}{*}{43.6010} \\
\hline & $\beta$ & 0.3042 & 0.1512 & & & & & \\
\hline \multirow{4}{*}{ KW } & $\alpha$ & 1.7884 & 2.5890 & \multirow{4}{*}{0.2187} & \multirow{4}{*}{0.0959} & \multirow{4}{*}{0.4999} & \multirow{4}{*}{45.6162} & \multirow{4}{*}{46.8265} \\
\hline & $\beta$ & 0.4544 & 1.7933 & & & & & \\
\hline & $\lambda$ & 8.9793 & 52.9562 & & & & & \\
\hline & $\theta$ & 1.3099 & 10.1035 & & & & & \\
\hline \multirow{3}{*}{ KITL } & $\alpha$ & 1.5511 & 0.5350 & \multirow{3}{*}{0.2242} & \multirow{3}{*}{0.0944} & & & \\
\hline & $\beta$ & 10.1497 & 9.1324 & & & 0.4895 & 43.5807 & 44.4885 \\
\hline & $\lambda$ & 0.3556 & 1.1931 & & & & & \\
\hline MVITI & $\alpha$ & 1.0353 & 0.2709 & & 01026 & & & \\
\hline 1VHNIL & $\beta$ & 0.9040 & 0.1948 & $0 . \angle J \angle J$ & 0.1030 & ד & 42.1398 & 42.1049 \\
\hline & $\alpha$ & 1.3963 & 0.3356 & & & & & \\
\hline OWITL & $\beta$ & 55.1455 & 193.5675 & 0.2173 & 0.0943 & 0.4919 & 43.5921 & 44.4998 \\
\hline & $\lambda$ & 0.0780 & 0.1781 & & & & & \\
\hline
\end{tabular}


Table 8. MLE with SE and other metrics: Group 2.

\begin{tabular}{|c|c|c|c|c|c|c|c|c|}
\hline & & Estimates & SE & KS & CVM & AD & AIC & BIC \\
\hline ITL & $\delta$ & 2.0929 & 0.6618 & 0.2130 & 0.0520 & 0.2973 & 32.7512 & 33.0537 \\
\hline \multirow{2}{*}{ NEITL } & $\theta$ & 0.8260 & 1.5968 & \multirow{2}{*}{0.2018} & \multirow{2}{*}{0.0405} & \multirow{2}{*}{0.2400} & \multirow{2}{*}{31.6464} & \multirow{2}{*}{32.2516} \\
\hline & $\delta$ & 3.8521 & 8.1014 & & & & & \\
\hline \multirow{3}{*}{ EL } & $\alpha$ & 7.0316 & 22.8576 & \multirow{3}{*}{0.2174} & \multirow{3}{*}{0.0527} & \multirow{3}{*}{0.2983} & \multirow{3}{*}{33.3300} & \multirow{3}{*}{34.2377} \\
\hline & $\beta$ & 3.1443 & 7.0486 & & & & & \\
\hline & $\lambda$ & 1.1988 & 6.2228 & & & & & \\
\hline \multirow{2}{*}{ ExEx } & $\alpha$ & 6.3206 & 23.1429 & \multirow{2}{*}{0.1789} & \multirow{2}{*}{0.0621} & \multirow{2}{*}{0.4414} & \multirow{2}{*}{33.7072} & \multirow{2}{*}{34.3124} \\
\hline & $\beta$ & 0.0589 & 0.2375 & & & & & \\
\hline \multirow{2}{*}{ W } & $\alpha$ & 1.5527 & 0.3675 & \multirow{2}{*}{0.7012} & \multirow{2}{*}{0.0505} & \multirow{2}{*}{0.3002} & \multirow{2}{*}{32.4143} & \multirow{2}{*}{33.0195} \\
\hline & $\beta$ & 0.3519 & 0.1683 & & & & & \\
\hline \multirow{4}{*}{ KW } & $\alpha$ & 7.7574 & 0.0025 & \multirow{4}{*}{0.2124} & \multirow{4}{*}{0.0411} & \multirow{4}{*}{0.2415} & \multirow{4}{*}{33.5910} & \multirow{4}{*}{34.8013} \\
\hline & $\beta$ & 0.9910 & 0.0025 & & & & & \\
\hline & $\lambda$ & 70.4798 & 59.0513 & & & & & \\
\hline & $\theta$ & 0.1124 & 0.0366 & & & & & \\
\hline \multirow{3}{*}{ KITL } & $\alpha$ & 6.3918 & 26.4265 & \multirow{3}{*}{0.2233} & \multirow{3}{*}{0.0501} & \multirow{3}{*}{0.2878} & \multirow{3}{*}{33.0906} & \multirow{3}{*}{33.9984} \\
\hline & $\beta$ & 0.2378 & 0.8625 & & & & & \\
\hline & $\lambda$ & 12.4011 & 40.8768 & & & & & \\
\hline
\end{tabular}

Table 9. MLE, MPS, and Bayeisan for reliability of the S-S model.

\begin{tabular}{|c|c|c|c|c|c|c|c|c|c|}
\hline & \multicolumn{3}{|c|}{ MLE } & \multicolumn{3}{|c|}{ MPS } & \multicolumn{3}{|c|}{ Bayesian } \\
\hline & Estimates & SE & $\mathbf{R}$ & Estimates & SE & $\mathbf{R}$ & Estimates & SE & $\mathbf{R}$ \\
\hline$\theta_{1}$ & 0.4246 & 0.4226 & \multirow{4}{*}{0.6123} & 0.4143 & 0.4163 & \multirow{4}{*}{0.6345} & 0.5423 & 0.3812 & \multirow{4}{*}{0.6743} \\
\hline$\delta_{1}$ & 5.6440 & 5.1041 & & 5.4284 & 4.9402 & & 6.6363 & 4.5001 & \\
\hline$\theta_{2}$ & 0.8312 & 1.6372 & & 0.8312 & 1.2626 & & 1.1196 & 0.8512 & \\
\hline$\delta_{2}$ & 3.8267 & 8.2125 & & 3.8267 & 7.4954 & & 4.8956 & 3.8509 & \\
\hline
\end{tabular}
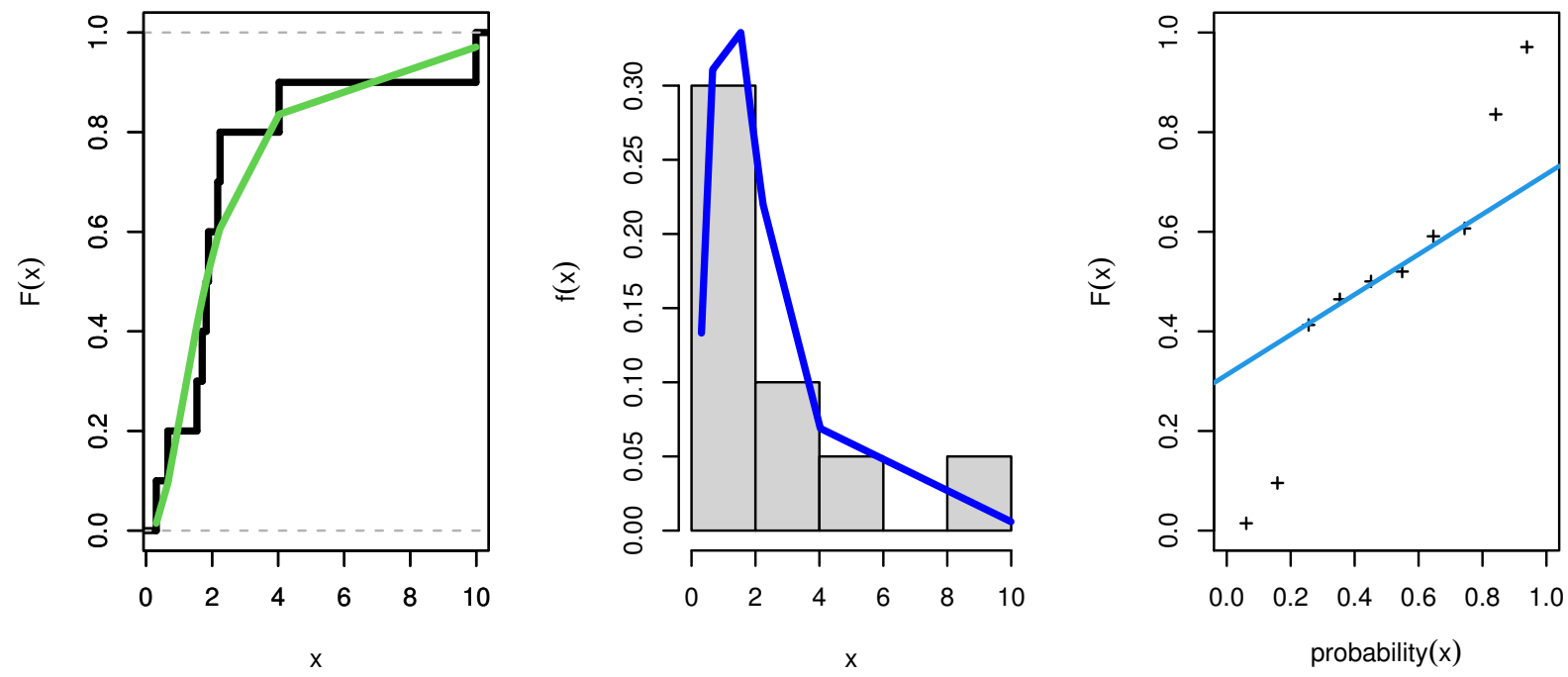

Figure 7. PDF, CDF and PP plot of the NEITL distribution: Group 1. 

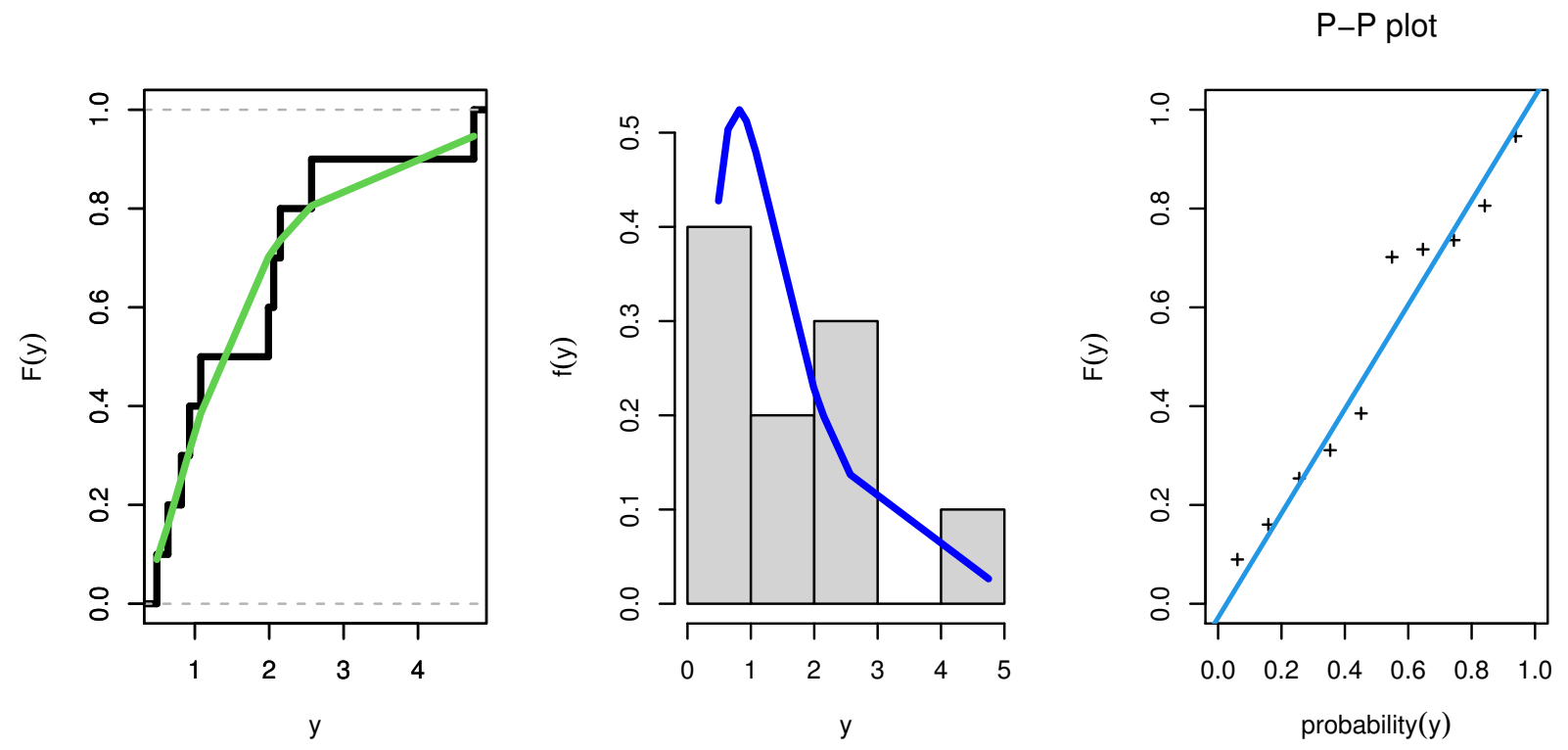

Figure 8. PDF, CDF, and PP plot of the NEITL distribution: Group 2.

Figures 9 and 10 show convergence plots of MCMC for parameter estimates of the NEITL distribution.
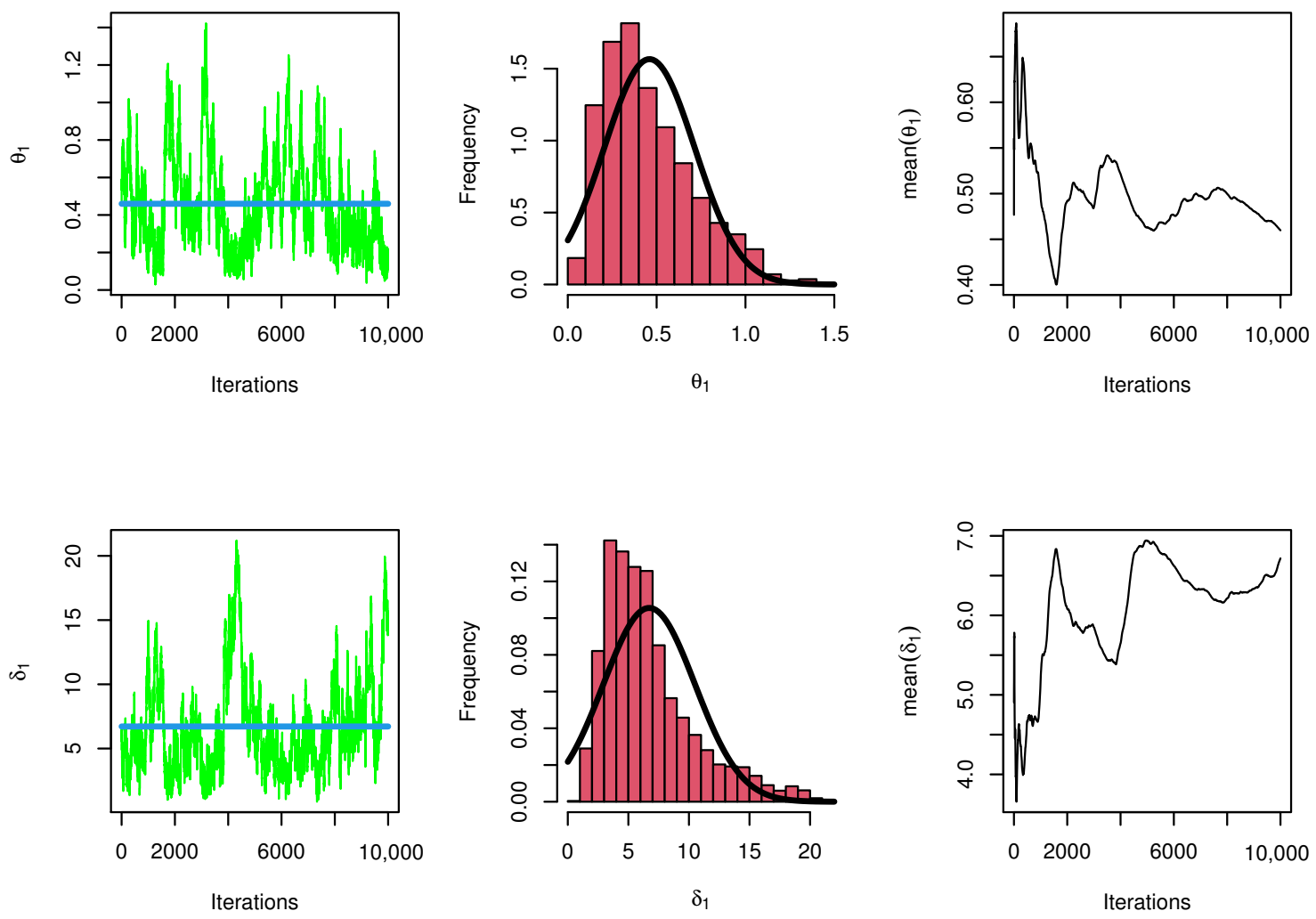

Figure 9. Trace, proposed distribution, and convergence of MCMC results for $\theta_{1}, \delta_{1}$. 

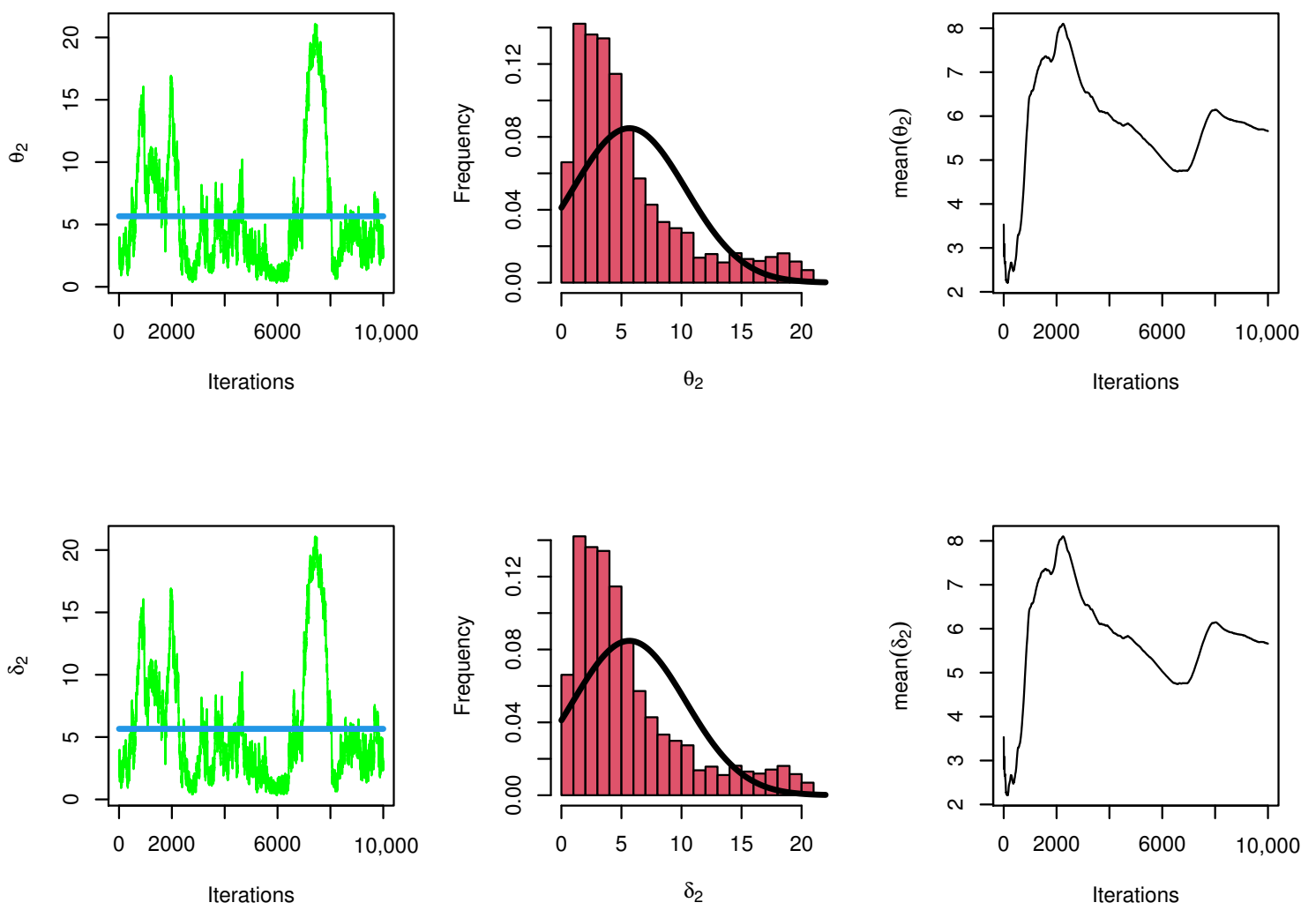

Figure 10. Trace, proposed distribution, and convergence of MCMC results for $\theta_{2}, \delta_{2}$.

\section{Conclusions}

A new two-parameter lifetime model, named "new exponential inverted Topp-Leone", is introduced in this paper. The new distribution gives more flexibility and wide applicability compared to the existing models. It appears that the shape of the distribution depends on the values of the parameters. Some of the novel hazard rates that can be used are: decreased, constant hazard rate, increasing hazard rate, upside down (reversed bathtub shape), and increasing-constant hazard rate. Several mathematical and distributional properties, such as ordinal moments, incomplete moments, quantile function, Renyi, and $\rho$ entropies, were described in detail. The new density is a linear combination of the well-known inverted Topp-Leone density. The reliability of stress strength was calculated. Using Bayesian and non-Bayesian estimation methods, the parameters of the NEITL distribution were estimated. In simulation research, statistical analysis was used to compare these methods in order to evaluate their effectiveness and investigate how these estimates perform for different sample sizes and parameter values. The simulation results indicate that the Bayes estimate performed the best in the smaller MSE sense. In most cases, we received large values near to one when calculating the S-S model's reliability, indicating that the model is of good quality. Furthermore, we propose using MPS estimation instead of ML estimation. To demonstrate the use of the novel distribution, two real-life datasets from the engineering and medical fields were studied. In addition, the use of these data in the stress-strength model has been validated. We hope that this distribution could be used in more areas.

Author Contributions: Conceptualization, A.S.H., E.M.A. and H.M.A.; methodology, A.S.H., E.M.A. and H.M.A.; software, A.S.H. and H.M.A.; formal analysis, A.S.M.M. and B.M.G.K.; investigation, H.M.A., A.S.M.M. and B.M.G.K.; resources, A.S.M.M.; data curation, A.S.H. and B.M.G.K.; writingoriginal draft preparation, A.S.H. and E.M.A. All authors have read and agreed to the published version of the manuscript. 
Funding: This work was funded by the Researchers Support Project (RSP-2021/363), King Saud University, Riyadh, Saudi Arabia.

Data Availability Statement: The data used to support the findings of this study are included within the article.

Conflicts of Interest: The authors declare no conflict of interest.

\section{References}

1. Huo, X.; Khosa, S.K.; Ahmad, Z.; Almaspoor, Z.; Ilyas, M.; Aamir, M. A new lifetime exponential-X family of distributions with applications to reliability data. Math. Probl. Eng. 2020, 2020, 1316345. [CrossRef]

2. Barco, K.V.P.; Mazucheli, J.; Janeiro, V. The inverse power Lindley distribution. Commun. Stat.-Simul. Comput. 2017, 46, 6308-6323. [CrossRef]

3. Abd AL-Fattah, A.M.; El-Helbawy, A.A.; Al-Dayian, G.R. Inverted Kumumaraswamy distribution: Properties and estimation. Pak. J. Stat. 2017, 33, 37-61.

4. Hassan, A.S.; Abd-Allah, M. On the inverse power Lomax distribution. Ann. Data Sci. 2019, 6, 259-278. [CrossRef]

5. Hassan, A.S.; Mohammed, R.E. Weibull inverse Lomax distribution. Pak. J. Stat. Oper. Res. 2019, 15, 587-603. [CrossRef]

6. Muhammed, H.Z. On the inverted Topp Leone distribution. Int. J. Reliab. Appl. 2019, 20, 17-28.

7. Hassan, A.S.; Mohammed, R.E. Parameter estimation of inverse exponentiated Lomax with right censored data. Gazi Univ. J. Sci. 2019, 32, 1370-1386.

8. Almetwally, E.M. Extended odd Weibull inverse Rayleigh distribution with application on carbon fibres. Math. Sci. Lett. 2021, 10, $5-14$.

9. Hassan, A.S.; Nassr, S.G. Parameter estimation of an extended inverse power Lomax distribution with Type I right censored data. Commun. Stat. Appl. Methods 2021, 28, 99-118. [CrossRef]

10. Hassan, A.S.; Elgarhy, M.; Ragab, R. Statistical properties and estimation of inverted Topp-Leone distribution. J. Stat. Appl. Probab. 2020, 9, 319-331.

11. Abushal, T.A.; Hassan, A.S.; El-Saeed, A.R.; Nassr, S.G. Power inverted Topp-Leone distribution in acceptance sampling plans. Comput. Mater. Contin. 2021, 67, 991-1011. [CrossRef]

12. Hassan, A.S.; Almetwally, E.M.; Ibrahim, G.M. Kumaraswamy inverted Topp-Leone distribution with applications to COVID-19 data. Comput. Mater. Contin. 2021, 68, 337-356. [CrossRef]

13. Ibrahim, G.M.; Hassan AS Almetwally, E.M.; Almongy, H.M. Parameter estimation of alpha power inverted Topp-Leone distribution with applications. Intell. Autom. Soft Comput. 2021, 29, 353-371. [CrossRef]

14. Almetwally, E.M.; Alharbi, R.; Alnagar, D.; Hafez, E.H. A new inverted Topp-Leone distribution: Applications to the COVID-19 mortality rate in two different countries. Axioms 2021, 10, 25. [CrossRef]

15. Almetwally, E.M. The odd Weibull inverse Topp-Leone distribution with applications to COVID-19 data. Ann. Data Sci. 2021, 1-20. [CrossRef]

16. Bantan, R.A.; Jamal, F.; Chesneau, C.; Elgarhy, M. Type II power Topp-Leone generated family of distributions with statistical inference and applications. Symmetry 2020, 12, 75. [CrossRef]

17. Abu El Azm, W.S.; Almetwally, E.M.; Alghamdi, A.S.; Aljohani, H.M.; Muse, A.H.; Abo-Kasem, O.E. Stressstrength reliability for exponentiated invertedWeibull distribution with application on breaking of jute fiber and carbon fibers. Comput. Intell. Neurosci. 2021, 2021, 4227346. [CrossRef]

18. Sabry, M.A.; Almetwally, E.M.; Alamri, O.A.; Yusuf, M.; Almongy, H.M.; Eldeeb, A.S. Inference of fuzzy reliability model for inverse Rayleigh distribution. AIMS Math. 2021, 6, 9770-9785. [CrossRef]

19. Yousef, M.M.; Almetwally, E.M. Multi stress-strength reliability based on progressive first failure for Kumaraswamy model: Bayesian and non-Bayesian estimation. Symmetry 2021, 13, 2120. [CrossRef]

20. Hassan, A.S.; Al-Omari, A.I.; Nagy, H.F. Stress-strength reliability for the generalized inverted exponential distribution using MRSS. Iran. J. Sci. Technol. Trans. A Sci. 2021, 45, 641-659. [CrossRef]

21. Haj Ahmad, H.; Almetwally, E. Marshall-Olkin generalized Pareto distribution: Bayesian and non Bayesian estimation. Pak. J. Stat. Oper. Res. 2020, 16, 21-33. [CrossRef]

22. Basheer, A.M.; Almetwally, E.M.; Okasha, H.M. Marshall-Olkin alpha power inverse Weibull distribution: Non Bayesian and Bayesian Estimations. J. Stat. Appl. Probab. 2020, 10, 327-345.

23. Cheng, R.C.H.; Amin, N.A.K. Estimating parameters in continuous univariate distributions with a shifted origin. J. R. Stat. Soc. Ser. B 1983, 45, 394-403. [CrossRef]

24. Almetwally, E.M.; Almongy, H.M.; Rastogi, M.K.; Ibrahim, M. Maximum product spacing estimation of Weibull distribution under adaptive type-II progressive censoring schemes. Ann. Data Sci. 2020, 7, 257-279. [CrossRef]

25. El-Sherpieny, E.S.A.; Almetwally, E.M.; Muhammed, H.Z. Progressive type-II hybrid censored schemes based on maximum product spacing with application to Power Lomax distribution. Phys. A Stat. Mech. Appl. 2020, 553, 124251. [CrossRef]

26. El-Sherpieny, E.S.A.; Almetwally, E.M.; Muhammed, H.Z. Bayesian and non-Bayesian estimation for the parameter of bivariate generalized Rayleigh distribution based on Clayton Copula under progressive type-II censoring with random removal. Sankhya A 2021, 1-38. [CrossRef] 
27. Almongy, H.M.; Alshenawy, F.Y.; Almetwally, E.M.; Abdo, D.A. Applying transformer insulation using Weibull extended distribution based on progressive censoring scheme. Axioms 2021, 10, 100. [CrossRef]

28. Haj Ahmad, H.; Salah, M.M.; Eliwa, M.S.; Ali Alhussain, Z.; Almetwally, E.M.; Ahmed, E.A. Bayesian and non-Bayesian inference under adaptive type-II progressive censored sample with exponentiated power Lindley distribution. J. Appl. Stat. 2021, 1-21. [CrossRef]

29. Bantan, R.; Hassan, A.S.; Almetwally, E.; Elgarhy, M.; Jamal, F.; Chesneau, C.; Elsehetry, M. Bayesian analysis in partially accelerated life tests for weighted Lomax distribution. Comput. Mater. Contin. 2021, 68, 2859-2875. [CrossRef]

30. Al-Omari, A.I.; Hassan, A.S.; Nagy, H.F.; Al-Anzi, A.R.A.; Alzoubi, L. Entropy Bayesian analysis for the generalized inverse exponential distribution based on URRSS. Comput. Mater. Contin. 2021, 69, 3795-3811. [CrossRef]

31. Al-Babtain, A.A.; Hassan, A.S.; Zaky, A.N.; Elbatal, I.; Elgarhy, M. Dynamic cumulative residual Rényi entropy for Lomax distribution: Bayesian and non-Bayesian methods. AIM Math. 2021, 6, 3889-3914. [CrossRef]

32. Hassan, A.S.; Zaki, A.N. Entropy Bayesian estimation for Lomax distribution based on record. Thail. Stat. 2021, 19, 96-115.

33. Bjerkedal, T. Acquisition of resistance in guinea pies infected with different doses of virulent tubercle bacilli. Am. J. Hyg. 1960, 72, 130-148. [PubMed]

34. Nelson, W. Applied Life Data Analysis; John Wiley \& Sons: New York, NY, USA, 1982. 